\title{
Seismic Response of a Concrete Filled Steel Tubular Arch Bridge to Spatially Varying Ground Motions Including Local Site Effect
}

\author{
Kaiming $\mathrm{Bi}^{1}{ }^{1}{ }^{*}$, Hong $\mathrm{Hao}^{1}$ and Wei-Xin Ren ${ }^{2}$ \\ ${ }^{1}$ School of Civil and Resource Engineering, the University of Western Australia, Crawley, WA 6009, Australia \\ ${ }^{2}$ School of Civil Engineering, Hefei University of Technology, China
}

(Received: 31 May 2012; Received revised form: 10 June 2013; Accepted: 17 July 2013)

\begin{abstract}
The construction of concrete filled steel tubular (CFST) arch bridge has become widespread all over the world and especially in China since 1990. This paper studies the nonlinear seismic response of a CFST arch bridge on a canyon site subjected to multi-component spatially varying ground motions. The threedimensional (3D) finite element (FE) model of the CFST arch bridge is developed with consideration of the material and geometric nonlinearities of the arch ribs. The spatially varying ground motions with consideration of wave passage effect, coherency loss effect and local site effect are stochastically simulated based on the combined one-dimensional (1D) wave propagation theory and spectral representation method. The effects of multi-component earthquake excitations, spatial variations of ground motions and varying site conditions on the seismic response of the CFST arch bridge are analysed. Numerical results show that for a reliable seismic analysis of a CFST arch bridge, multi-component earthquake excitations with consideration of ground motion spatial variations and local soil conditions should be considered.
\end{abstract}

Key words: CFST arch bridge, nonlinear seismic response, multi-component earthquake excitations, ground motion spatial variations, local site effect.

\section{NTRODUCTION}

The construction of concrete filled steel tubular (CFST) arch bridges has become widespread all over the world and especially in China in recent decades owing to the inherent advantages of this bridge type. For example, the infilled concrete prevents local buckling of the steel tube, while the steel tube confines the concrete to resist tension, bending moment and shear force, thus the composite structural action of the infilled concrete and the steel tube improves the member's load-carrying capacity. Moreover, the tube can act as a formwork for the concrete during the construction of the bridge, which saves a majority of construction cost (Wu et al. 2006). The first CFST arch bridge in China was completed in 1990. Since then, more than 300 CFST arch bridges have been built or are under construction.
Owing to the improved load-carrying capacity of CFST arch bridge, the span length of this kind of bridge can be longer than the conventional concrete arch bridge or steel arch bridge. For example, the span of Wuxia Yangtze River Bridge in China reaches $460 \mathrm{~m}$. For these long span structures, it is unrealistic to assume earthquake motions at multiple structural supports are the same because of the inevitable ground motion spatial variations. Many reasons may result in ground motion spatial variations. These include (1) the difference in the arrival times of seismic waves at different supports, denoted as the wave passage effect; (2) the coherency loss effect owing to the reflections and refractions of the waves in the heterogeneous media of the ground; and (3) the local site effect due to different local soil conditions (Der Kiureghian 1996). 
Many researchers have studied the seismic responses of arch structures to spatially varying ground motions. Hao (1993) analysed the in-plane stochastic responses of incompressible circular arches to spatially correlated horizontal multiple excitations and concluded that the responses may be underestimated or overestimated by neglecting the ground motion spatial variations, depending on the structure and ground motion properties, the locations where the responses are evaluated, and the response quantity under consideration. Hao (1995) then extended the work to analyse the responses of the incompressible circular arches to correlated simultaneous horizontal and vertical multiple excitations, and examined the effects of multiple horizontal and vertical excitations on arch asymmetric and symmetric vibration modes. It was found that vertical ground motion component might have significant effect on the arch responses. Harichandran et al. (1996) studied the seismic responses of two deck arch bridges to spatially varying ground motions and compared the results with the identical (uniform) and delayed (wave passage effect only) excitations. They concluded that the use of identical excitations is in general unacceptable for long-span bridges, and the use of delayed excitations is acceptable for the longitudinal response of short arch bridges. Zanardo et al. (2004) investigated the seismic responses of short span reinforced concrete arch bridges to multiple support excitations and also compared the results with conventionally used uniform input and multiple inputs with wave passage effect. They concluded that curved structures are very sensitive to multiple support excitations. Su et al. (2007) studied the seismic behaviour of a steel trussed arch to multisupport excitations. The numerical results indicated that horizontal multi-support excitations have a quite large amplification effect on the seismic responses of the trussed arch, whereas vertical multiple support excitations reduce the structural responses as compared with uniform excitations. Bai et al. (2010) investigated the seismic response of a large dimensional steel trussed arch structure subjected to the combined spatially varying horizontal and vertical ground motions, the influence of local site effect is also studied by using different classes of response spectrum to represent different local soil conditions. They concluded that the ground motion spatial variations as well as local site effect significantly influence the seismic responses of the trussed arch structure.

In terms of CFST arch bridge, previous studies mainly focused on the static and natural vibration analysis (Zong et al. 2005; Yoshimura et al. 2006; Nakamura et al. 2009). For the seismic response of
CFST arch bridge, Wu et al. (2006) performed a nonlinear seismic analysis of the Second Saikai Bridge by using the strong ground motions recorded in the Hyogo-ken Nanbu Earthquake in Japan. The nonlinear seismic response characteristics and seismic safety of this bridge were examined in detail by subjecting the bridge to earthquakes in the out-of-plane direction, longitudinal direction and the combined out-of-plane and longitudinal directions. However, it should be noted that the ground motion spatial variations are not considered in the paper, which may lead to inaccurate predictions of seismic responses. Zhao and Zhou (2007) and Bai (2008) studied the influence of spatially varying ground motions on the seismic response of long span CFST arch bridges. Both of these studies assumed the ground motion spatial variations are caused by wave passage effect and coherency loss effect only, and the influence of local site effect was ignored. These assumptions are valid only for structures located on the relatively flat-lying sites. For structures located at a canyon site as shown in Figure 1, the ground motion spatial variations will be further intensified by the local site effect. In fact, previous studies revealed that local site effect not only causes further phase difference (Der Kiureghian 1996), but also significantly affects the coherency loss between spatial ground motions (Bi and Hao 2011). These differences in turn will significantly affect the structural responses (Bai et al. 2010; Bi and Hao 2010). To the best knowledge of the authors, a comprehensive nonlinear seismic analysis of a CFST arch bridge subjected to multi-component spatially

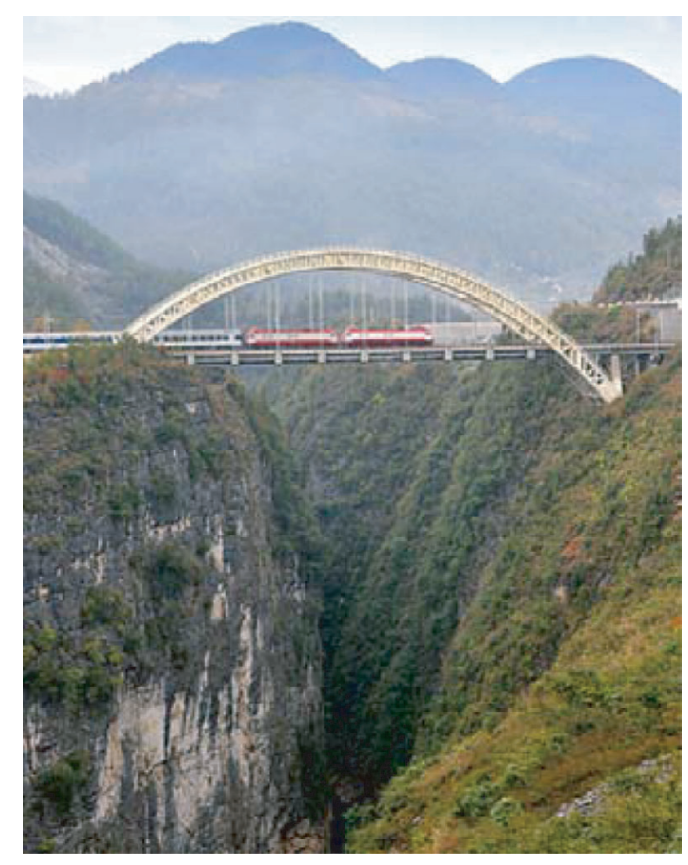

Figure 1. A photograph of the Yeshan River Bridge 
varying ground motions with consideration of wave passage, coherency loss and local site effects has not been reported.

This paper studies the nonlinear seismic response of a CFST arch bridge to multi-component spatially varying ground motions. The 3D FE model of the bridge is developed in ANSYS (2009), the material and geometric nonlinearities of the concrete and the steel tube in the arch ribs are considered. The spatially varying ground motions are simulated based on the combined one-dimensional (1D) wave propagation theory and spectral representation method (Bi and Hao 2012). The base rock motions at different locations are assumed to have the same intensity and are modelled by a filtered Tajimi-Kanai power spectral density function (PSD). The spatial variations of base rock motions are considered by an empirical coherency loss function. The PSDs of the surface motions are derived based on the deterministic $1 \mathrm{D}$ wave propagation theory by assuming the base rock motions consisting of out-of-plane $\mathrm{SH}$ wave and combined $\mathrm{P}$ and SV waves propagating into the site with an assumed incident angle. The 3D spatially varying ground surface time histories at different supports of the bridge are then stochastically simulated based on the traditional spectral representation method. The simulated ground motion time histories are applied as inputs to the multiple bridge supports. The structural responses are formulated by using the large mass method (LMM) (Leger et al. 1990). The influences of multi-component earthquake excitations, ground motion spatial variations and varying site conditions on the seismic responses of the CFST arch bridge are analysed.

\section{BRIDGE MODEL}

\subsection{Bridge Description}

The bridge to be investigated in this study is the Yeshan River Bridge, which is a half-through CFST arch bridge in China. Figure 1 shows a photograph of the bridge and the elevation and plan view is shown in Figure 2. The total length of the bridge is $138.65 \mathrm{~m}$ and the arch span length is $124 \mathrm{~m}$. Owing to the specific geological conditions of local sites, an asymmetric arc was used in the design. The length of the left half span [Yichang direction in Figure 2(a)] is $70.375 \mathrm{~m}$ with a rise at the crown of $40 \mathrm{~m}$, giving a rise-span ratio of 1: 3.52. For the right half span [Wanzhou direction in Figure 2(a)], the length and rise are 53.625 and $24.15 \mathrm{~m}$, respectively, and the rise-span ratio is $1: 4.44$. Because of the asymmetric configuration of the bridge, the springing position of the right span is $15.85 \mathrm{~m}$ higher than that of the left span. The width of the bridge is $15.3 \mathrm{~m}$ as shown in Figure 2(b). The bridge is located at a V-shaped canyon site, the elevation between the bridge deck and

(a)

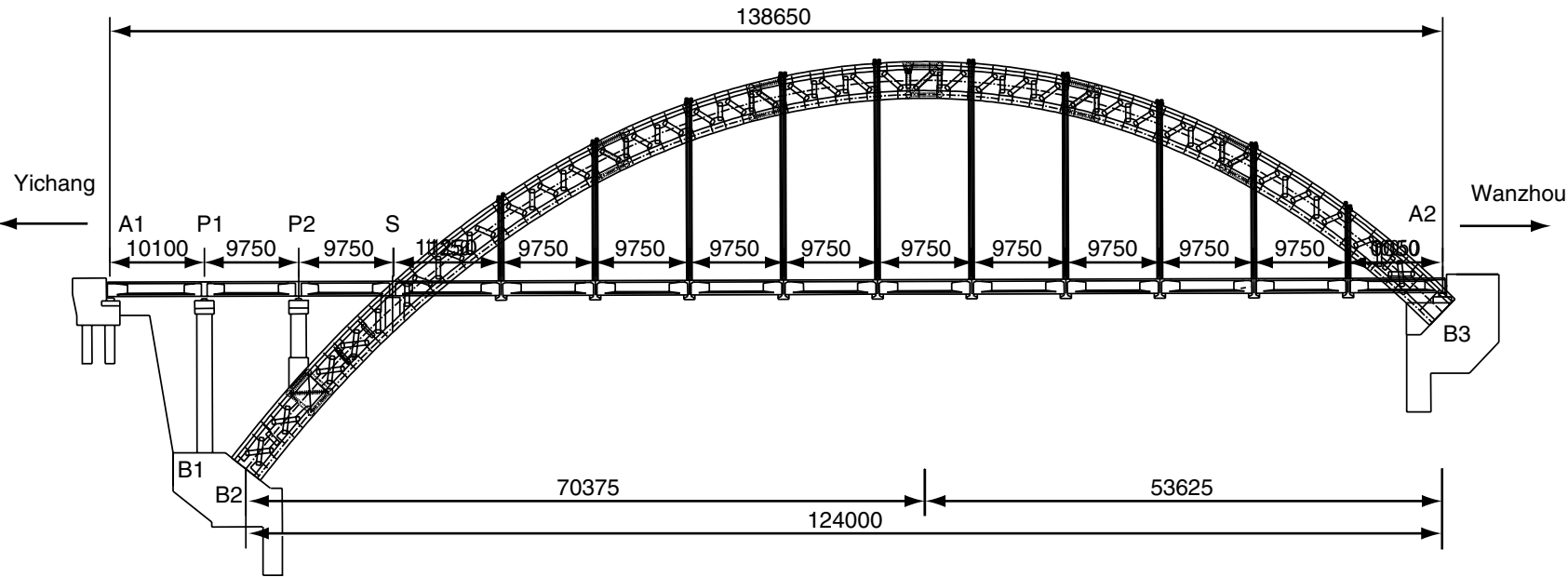

(b)

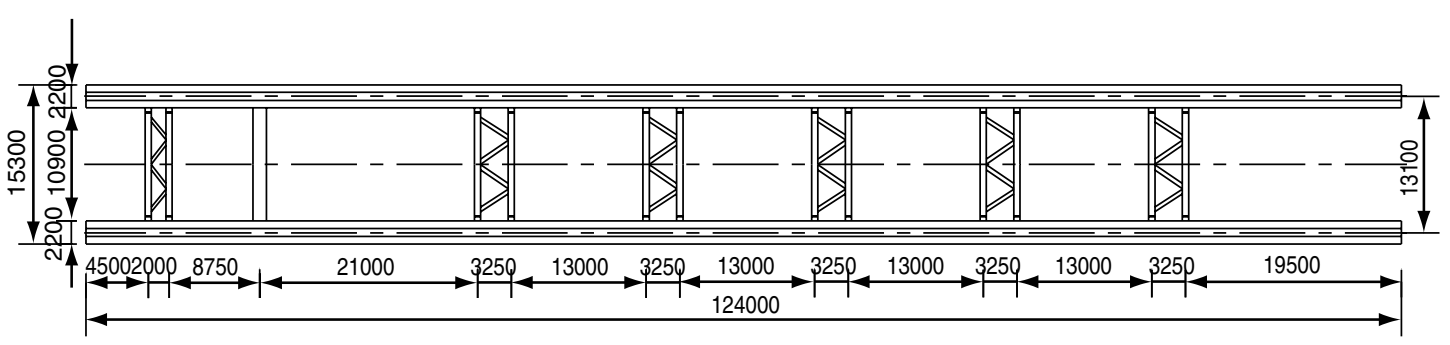

Figure 2. (a) Elevation view of the bridge; (b) plan view of the arch structure (unit: $\mathrm{mm}$ ) 
the base rock is about $160 \mathrm{~m}$ (as shown in Figure 1) based on the geological report of the bridge site.

The bridge has two parallel arch ribs, with the centreto-centre distance of $13.1 \mathrm{~m}$ as shown in Figure 2(b). Each arch rib consists of two dumbbell-type cross section members (the upper chord and lower chord). These two members are connected by the H-type steel webs as shown in Figure 3(a). The depth and width of each arch rib are 3.8 and $2.2 \mathrm{~m}$ respectively. The four steel tubes of each arch rib have an outer diameter of $800 \mathrm{~mm}$ and a thickness that varies depending on the position of the arch rib (24, 20 and $16 \mathrm{~mm})$. High fluidity concrete fills the four steel tubes and the confined space between the steel plates of the upper and lower chords as shown in Figure 3(a). The two parallel arch ribs are connected by 6 spatial cross-bracing systems and a horizontal stiffening girder as shown in Figure 2(b). The deck system consists of $5 \mathrm{~T}$ beams with the height of $1.5 \mathrm{~m}$ arranged longitudinally at a spacing of $2.14 \mathrm{~m}$. The $\mathrm{T}$ beams are connected by 15 transverse diaphragms with the height of $2 \mathrm{~m}$. Figure 3(b) shows the cross section of the deck system. The arch ribs and the deck system are connected vertically by 20 suspenders. Each suspender consists of 127 smaller steel wires each with a diameter of $5.5 \mathrm{~mm}$. On the left span of the bridge, two piers are designed to support the deck system, with pier $1(\mathrm{P} 1)$ on the arch support and pier 2 (P2) supported by the upper chord of the arch ribs as shown in Figure 2(a).

(a)

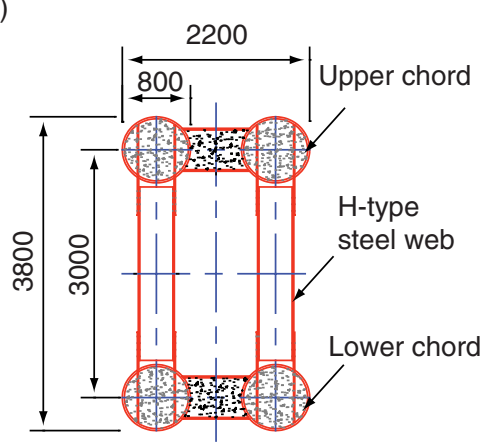

(b)

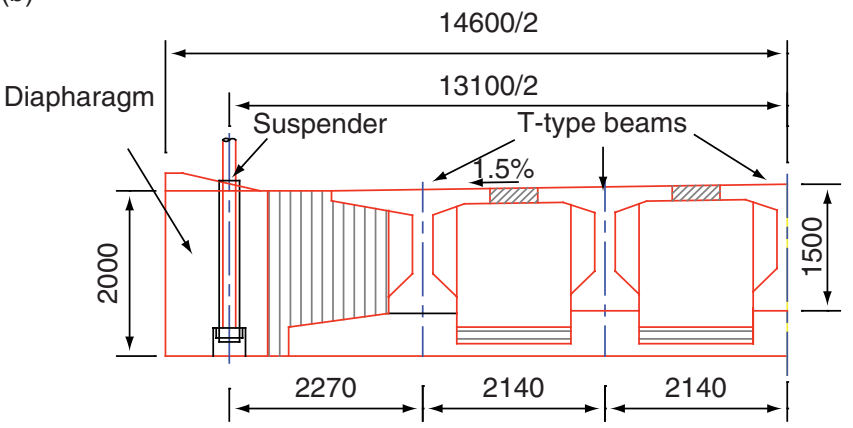

Figure 3. Cross sections of main bridge components: (a) arch rib;

(b) deck system (not to scale, unit: $\mathrm{mm}$ )

\subsection{Finite Element Model}

A 3D FE model of the Yeshan River Bridge was developed in ANSYS (2009). The arch ribs, H-type webs, lateral bracings, stiffening girder, the deck system and the piers are modelled using 3D beam elements (BEAM188) based on the actual cross-sectional properties. All suspenders are modelled as truss elements (LINK10). It should be noted that each CFST arch rib consists of the steel tube and infilled concrete. These two components are modelled separately but with sharing nodes in the model. In other words, perfect bonding between concrete and steel is assumed, and two elements are included between every two nodes, with one element for the steel tube and another for the concrete. Regarding the boundary conditions, the springing positions of the arch ribs and the bases of $\mathrm{P} 1$ are fixed in all degrees of freedom (DOFs). The deck system is simply supported, with the three translational DOFs at each node of the left and right ends of the girder (A1 and A2 in Figure 4) fixed except the longitudinal DOFs at A2 released. The vertical and transverse DOFs of the nodes on the top of the piers and the stiffening girder are coupled with the corresponding nodes on the deck system (locations $\mathrm{C} 1, \mathrm{C} 2$ and $\mathrm{C} 3$ in Figure 4). Figure 4 shows the 3D FE model of the bridge.

For long span structures, nonlinear analysis is essential to evaluate the stresses and deformations induced not only by static loads but also by dynamic loads. Both geometric and material nonlinearities are considered in the analysis. Since CFST arch ribs are the main load-bearing components of the bridge, to reduce computational time, material nonlinearities are only considered for steel tube and infilled concrete in the arch ribs. Other structural components such as deck, lateral bracing and stiffening girders are modelled by linear elastic material property assumption. The elasticperfect plastic model is usually suggested to consider

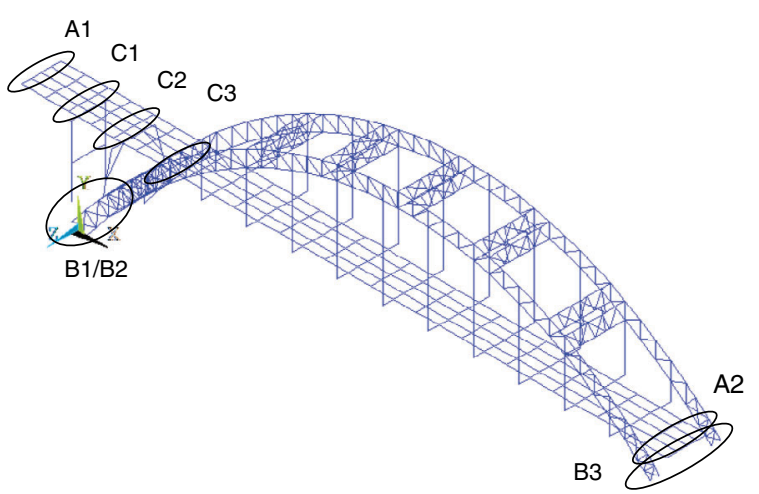

Figure. 4. 3D FE model of Yeshan River Bridge 
the nonlinear behaviour of steel tube in many design codes such as JRA (2002). This model is adopted in the study. Figure 5(a) shows the stress-strain curve of the steel tube, where $\sigma_{s y}$ is the yield stress and is assumed to be $345 \mathrm{MPa}$. The stress-strain curve adopted by $\mathrm{Wu}$ et al. (2006), which takes into account the confinement of the infilled concrete, is used to determine the material nonlinearity of the infilled concrete. Figure 5(b) shows the stress-strain relation of the confined concrete. The yield stress and yield strain are calculated using the following equations:

$$
\begin{gathered}
\sigma_{c B}=-\left\{\sigma_{c k}+0.8(2 t / D) \sigma_{s y}\right\} \\
\varepsilon_{c B}=-\left(2.5+0.025 \sigma_{c k}\right) \times 10^{-3}\left(\sigma_{c k}: M P a\right)
\end{gathered}
$$

where $\sigma_{c B}$ is the yield stress, $\varepsilon_{c B}$ is the yield strain, $\sigma_{c k}$ is the specified concrete strength and is assumed to be 30 MPa, $t$ is the thickness of the steel tube and $D$ is the outer diameter of the steel tube.

It is widely accepted that the accuracy of a FE analysis is greatly affected by the finite element size. In the present study, the element size is generally $1 \mathrm{~m}$. To carry out a convergence test, another two element sizes $(0.5 \mathrm{~m}$ and $2 \mathrm{~m})$ were also adopted. It was found that the $0.5 \mathrm{~m}$ and $1 \mathrm{~m}$ element sizes result in almost the same results, and the $1 \mathrm{~m}$ size can significantly reduce the computational effort. $1 \mathrm{~m}$ element size is therefore used in the present study.

(a)

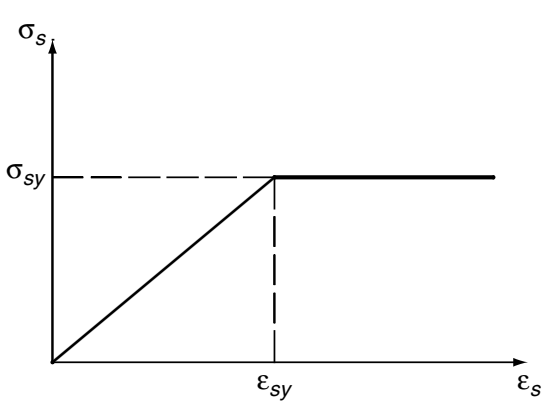

(b)

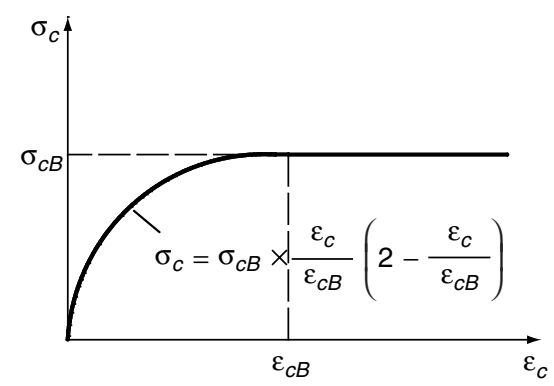

Figure 5. Stress-strain curve of the arch rib: (a) steel tube; (b) concrete

\subsection{Natural Vibration Characteristics}

With the detailed FE model as described above, the vibration frequencies and the corresponding vibration modes of the bridge can be obtained by carrying out an eigenvalue analysis. Since dead load will influence the dynamic characteristics of bridge structures (Ren and Obata 1999), when performing the eigenvalue analysis, the self-weight of the structure is applied first, and the computation starts from the dead load deformed configuration. Figure 6 shows the first seven vibration mode shapes and the corresponding frequencies. It is shown that the first three vibration modes are in the transverse direction with the fundamental frequency of $0.6873 \mathrm{~Hz}$, Mode 4 is the first vertical mode with a frequency of $1.5931 \mathrm{~Hz}$ and mode 7 is the first torsional mode with a frequency of $2.7429 \mathrm{~Hz}$.

\section{SPATIALLY VARYING GROUND MOTIONS}

The span length of Yeshan River Bridge reaches $138.65 \mathrm{~m}$, the wave passage and coherency loss effect will inevitably result in the spatially varying ground motions. Furthermore, the asymmetric bridge is located at a canyon site as shown in Figure 1, the elevations of different supports are different and the local soil conditions under different supports may vary as well, the ground motion spatial variations are thus further intensified by the local site effect. Traditional method for simulating the spatially varying ground motions (e.g. Hao et al. 1989) is based on the flat-lying site assumption and the influence of local site effect is not considered. With such an assumption, ground motions at different locations have the same intensity and frequency contents. These traditional methods thus are not suitable to simulate the spatially varying ground motions of a canyon site as shown in Figure 1. More recently, Bi and Hao (2012) developed an approximate approach to stochastically simulate the spatially varying motions on the ground surface of a canyon site with varying site conditions. In the method, the base rock motions are assumed to consist of out-of-plane SH wave and in-plane combined $\mathrm{P}$ and $\mathrm{SV}$ waves propagating into the site with an assumed incident angle. The power spectral density function on the base rock is assumed the same, and is modelled by a filtered Tajimi-Kanai power spectral density function (Tajimi 1960). The spatial variation of ground motions at base rock is modelled by an empirical coherency loss function. The base rock waves then propagate vertically to the ground surface and local site effect is modelled using the deterministic 1D wave propagation theory (Wolf 1985). The PSDs of the horizontal in-plane, horizontal out-of-plane and vertical inplane motions on the ground surface can thus be formulated by considering the site transfer functions in the 


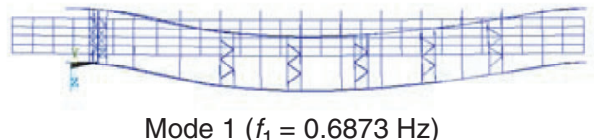

Mode $1\left(f_{1}=0.6873 \mathrm{~Hz}\right)$

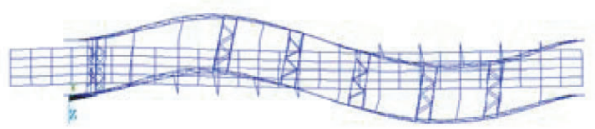

Mode $3\left(f_{3}=1.4576 \mathrm{~Hz}\right)$

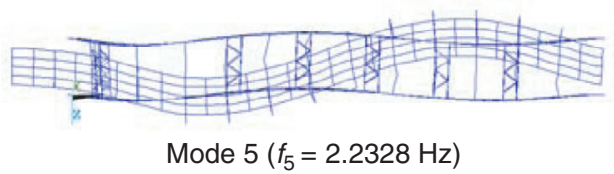

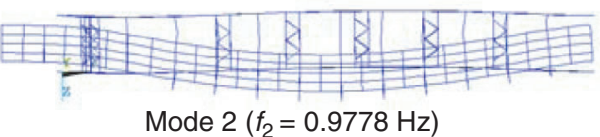
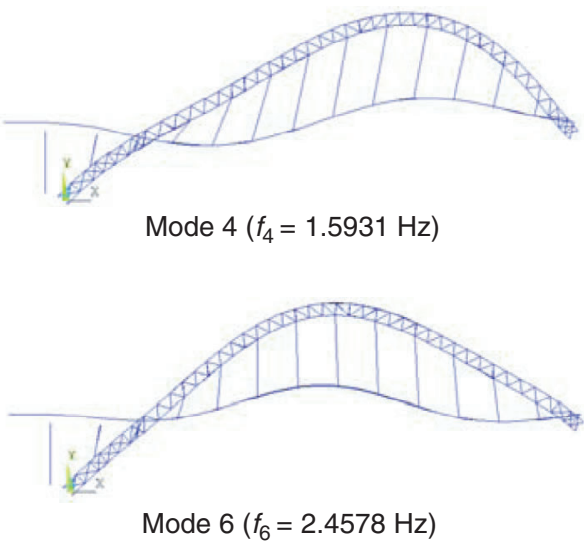

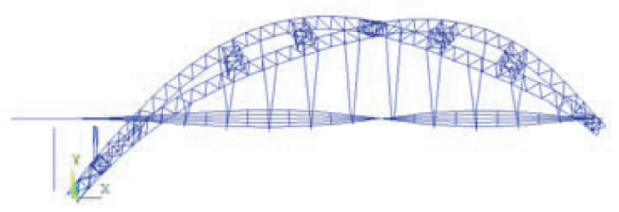

Mode $7\left(f_{7}=2.7429 \mathrm{~Hz}\right)$

Figure 6. First seven vibration mode shapes and corresponding frequencies of the bridge

corresponding directions. The 3D spatially varying ground motions can then be simulated by using the approach similar to the traditional method. This approach directly relates site amplification effect with local soil conditions, and can capture the multiple vibration modes of local site, is believed more realistically simulating the multicomponent spatially varying motions on surface of a canyon site. Detailed information about the simulation technique can be found in Bi and Hao (2012).

To model the spatial ground motions, in this study, the horizontal base rock motions are assumed to be the same and have the following form:

$$
\begin{aligned}
& S_{g}(\omega)=\frac{\omega^{4}}{\left(\omega_{f}^{2}-\omega^{2}\right)^{2}+\left(2 \omega_{f} \omega \xi_{f}\right)^{2}} \\
& \frac{1+4 \xi_{g}^{2} \omega_{g}^{2} \omega^{2}}{\left(\omega_{g}^{2}-\omega^{2}\right)^{2}+4 \xi_{g}^{2} \omega_{g}^{2} \omega^{2}} \Gamma
\end{aligned}
$$

where $\omega_{g}$ and $\xi_{g}$ are the central frequency and damping ratio of the Tajimi-Kanai power spectral density function, $\omega_{f}$ and $\xi_{f}$ are the corresponding central frequency and damping ratio of the high pass filter function. These parameters can be fitted from previous recorded data on rock sites and they are assumed as $\omega_{g}=10 \pi \mathrm{rad} / \mathrm{s}, \omega_{f}=$ $0.5 \pi, \xi_{f}=0.6$, in the present study. $\Gamma$ is a scaling factor depending on the ground motion intensity and time duration. In the present study, the PGA of the base rock motion is assumed to be $0.5 \mathrm{~g}$, and the duration is $\mathrm{T}=20$ s. $\Gamma$ is found to be $0.022 \mathrm{~m}^{2} / \mathrm{s}^{3}$ based on the standard random vibration method (Der Kiureghian 1980). Previous recorded earthquake time histories reveal that the vertical components are usually smaller than those in the horizontal directions. Many of the seismic design codes, e.g., the American code (UBC97), assume the vertical component of the ground motion to be $1 / 2$ to $2 / 3$ of the horizontal component. In the present study, the vertical motion on the base rock is modelled with the same filtered Tajimi-Kanai power spectral density function (Eqn 3), but the amplitude is assumed to be $2 / 3$ of the horizontal component. Figure 7 shows the simulated horizontal and vertical motions on the base rock.

The Sobczyk model (Sobczyk 1991) is selected to describe the coherency loss between the ground motions at points $j$ ' and $k$ ' on the base rock (where $j, k$ represent the foundations of the bridge, which are locations A1, $\mathrm{B} 1, \mathrm{~B} 2, \mathrm{~B} 3$ and $\mathrm{A} 2$ in Figure 2(a), $j, k$, are the 


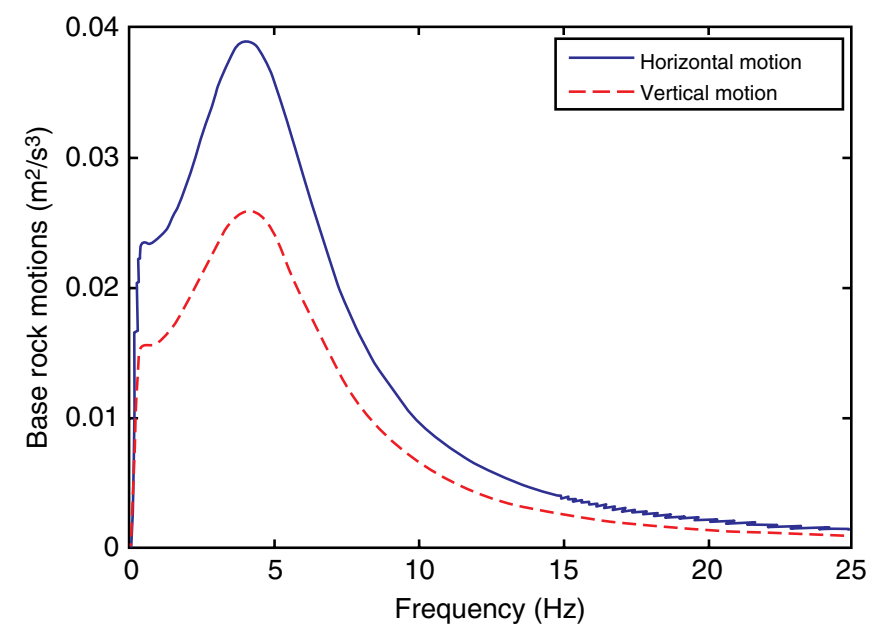

Figure 7. PSDs of base rock motions

corresponding points on the base rock which are right beneath different foundations of the bridge):

$$
\begin{aligned}
\gamma_{j^{\prime} k^{\prime}}(i w) & =\left|\gamma_{j^{\prime} k^{\prime}}(i w)\right| \exp \left(-i \omega d_{j^{\prime} k^{\prime}} \cos \alpha / v_{a p p}\right) \\
& =\exp \left(-\beta \omega d_{j^{\prime} k^{\prime}}^{2} / v_{a p p}\right) . \\
& \exp \left(-i \omega d_{j^{\prime} k^{\prime}} \cos \alpha / v_{a p p}\right)
\end{aligned}
$$

where $\beta$ is a coefficient reflecting the level of coherency loss and $\beta=0.0015$ is assumed in the present study, which represents an intermediately correlated ground motions. As shown in Figure 2(a), Point B1 is close to B2 and B3 is next to A2, thus the ground motions at points $\mathrm{B} 1$ and $\mathrm{B} 2$ can be assumed the same, For the ground motions at points B3 and A2, the same assumption is also made. Thus in this study, the spatially varying ground motions at three locations, i.e., at locations A1, B1 and B3, are needed to be simulated as inputs for bridge response analysis. The distances between different locations are $d_{A 1^{\prime} B 2^{\prime}}=$ $14.65 \mathrm{~m}, d_{B 2^{\prime} B 3^{\prime}}=124 \mathrm{~m}$ and $d_{A 1^{\prime} B 3^{\prime}}=138.65 \mathrm{~m}$ respectively. $v_{\text {app }}$ is the apparent wave velocity on the base rock, which is related to the base rock property and incident angle $\alpha$. With the given properties of local site (shown in Table 1) and assumed incident angle $\alpha=45^{\circ}, v_{\text {app }}$ equals $1200 \mathrm{~m} / \mathrm{sin}$ the present study.
As shown in Figure 1, the bridge is located at a firm rock site. To study the influence of different soil conditions, a relatively soft soil layer is also considered. Table 1 shows the parameters for different soil conditions and base rock. It should be noted that, when an arch bridge is located at a soft soil site, pile foundations are usually designed to resist the large axial force. In this case, the interaction between the structure and the surrounding soil (SSI effect) will further alter the structural responses (Bi et al. 2011). Not to further complicate the problem, the SSI effect is not considered in the present study even when relatively soft soil is considered.

With the proposed approach (Bi and Hao 2012) and the given parameters of local site, the non-stationary horizontal in-plane, horizontal out-of-plane and vertical in-plane motions on the ground surface are simulated. In the simulation, the sampling frequency and the upper cut-off frequency are set to be 100 and $25 \mathrm{~Hz}$ respectively, and the time duration is assumed to be $T=20 \mathrm{~s}$. It should be noted that during the simulation, the stationary processes are first generated, and the non-stationary motions are obtained by applying an envelope function to modulate the amplitudes of the stationary processes. Figure 8 shows the simulated $3 \mathrm{D}$ spatially varying acceleration time histories at different supports of Case 7 (Table 2), and Figure 9 shows the corresponding displacement time histories. Figure 10 shows the comparisons of the simulated PSDs with the theoretical values of the horizontal in-plane motions, good agreements are observed. For conciseness, the comparisons of horizontal out-of-plane and vertical in-plane motions are not plotted, good agreements are also observed. It is obvious that the PSDs of ground surface motions are different from that on the base rock (Figure 7), ground surface PSDs may consist of multiple distinctive peaks. This is because seismic wave will be amplified and filtered when propagating through a layered soil site and the amplifications can occur at various vibration modes of the site. These different local amplification effects in turn result in different ground displacement as shown in Figure 9. It is obvious that softer soil leads to larger displacements at the corresponding foundation. The comparisons of model

Table 1. Parameters for local site conditions

\begin{tabular}{lcccc}
\hline Type & Density $\left(\mathbf{k g} / \mathbf{m}^{\mathbf{3}}\right)$ & Shear modulus $(\mathbf{M P a})$ & Damping ratio & Poisson's ratio \\
\hline Base rock & 2500 & 1800 & 0.05 & 0.33 \\
Firm soil & 2000 & 800 & 0.05 & 0.4 \\
Soft soil & 1800 & 200 & 0.05 & 0.4 \\
\hline
\end{tabular}




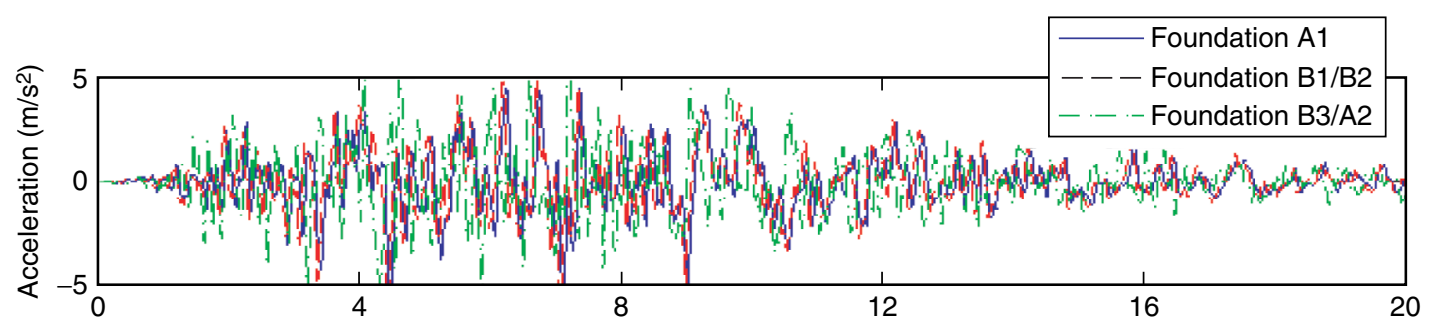

(a) Horizontal in-plane motion

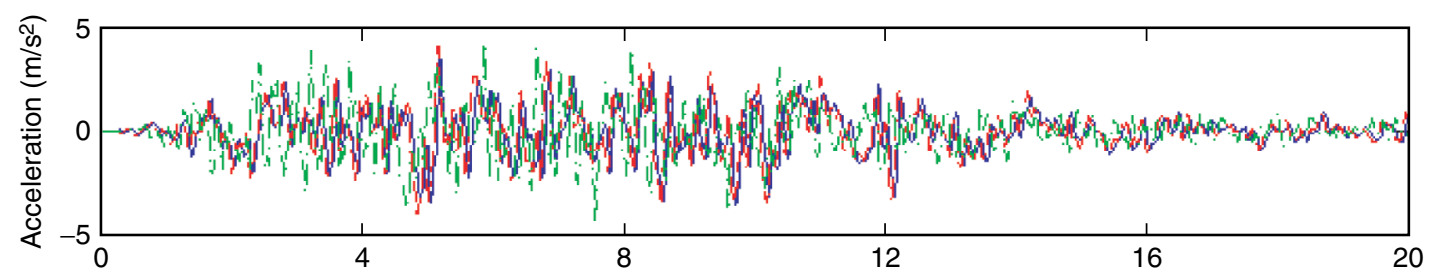

(b) Horizontal out-of-plane motion

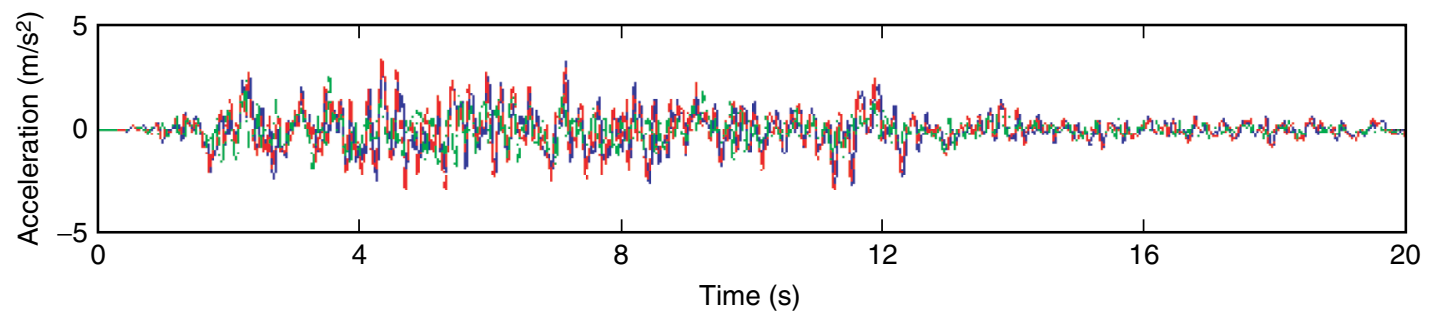

(c) Vertical in plane motion

Figure 8. Simulated acceleration time histories at different foundations (Case 7)

Table 2. Different cases studied

\begin{tabular}{lccc}
\hline Case No & Seismic component & Coherency & Site condition \\
\hline 1 & 1D (longitudinal) & Uniform & FFF \\
2 & 2D (longitudinal + vertical) & Uniform & FFF \\
3 & 3D (longitudinal + vertical + transverse) & Uniform & FFF \\
4 & 3D & Wave passage only & FFF \\
5 & 3D & Spatially varying & FFF \\
6 & 3D & Spatially varying & SSS \\
7 & 3D & Spatially varying & SSF \\
\hline
\end{tabular}

and simulated coherency loss function between different motions on the base rock are shown in Figure 11. Good agreement can be observed except for $\left|\gamma_{A 1^{\prime} B 3^{\prime}}\right|$ and $\left|\gamma_{B 1^{\prime} B 3^{\prime}}\right|$ in the high frequency range. This is, however, expected because as the distance increases, the cross correlation between the spatial motions or their coherency values decrease rapidly with the frequency. Previous studies (e.g. Hao et al. 1989) revealed that the coherency value of about $0.3-0.4$ is the threshold of cross correlation between two time histories because numerical calculations of coherency function between any two white noise series result in a value of about 0.3-0.4. Therefore, the calculated coherency loss between two simulated time histories remains at about 0.4 even the model coherency function decreases below this threshold value. For the coherency loss function between the motions on the ground surface, Bi and Hao (2011) demonstrated that it is different from that on the base rock. The spatial ground motions on ground surface are related to the spectral ratios of two local site transfer functions, and they are least correlated when the ratios are far from unity. More detailed discussions on the influences of local site conditions on ground motion spatial variations can be found in (Bi and Hao 2011).

The simulated horizontal in-plane, vertical in-plane and horizontal out-of-plane motions are applied as inputs at different foundations of the bridge in the longitudinal, vertical and transverse directions respectively in bridge response analysis. 


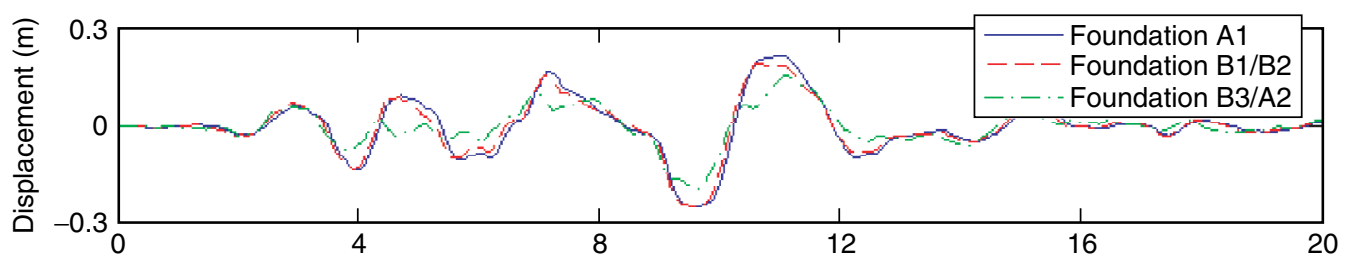

(a) Horizontal in-plane motion

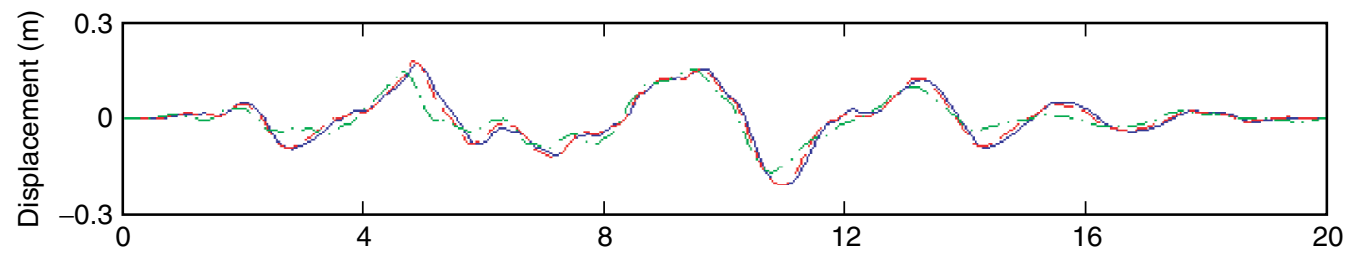

(b) Horizontal out-of-plane motion

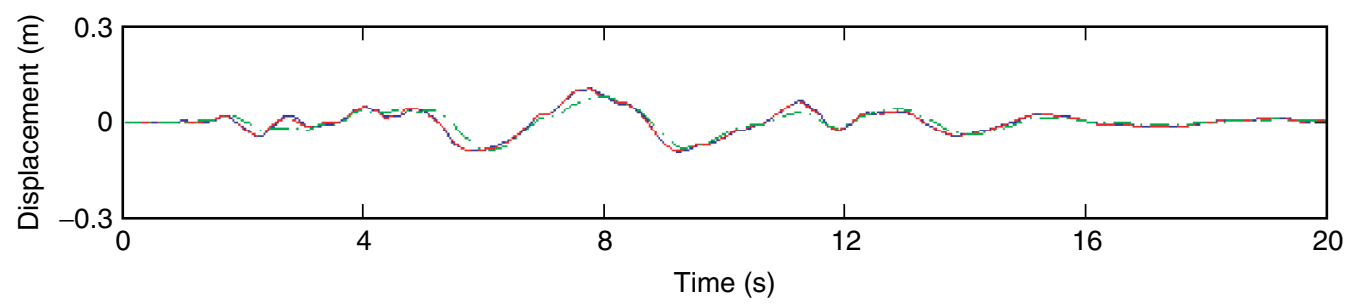

(c) Vertical in-plane motion

Figure 9. Simulated displacement time histories at different foundations (Case 7)
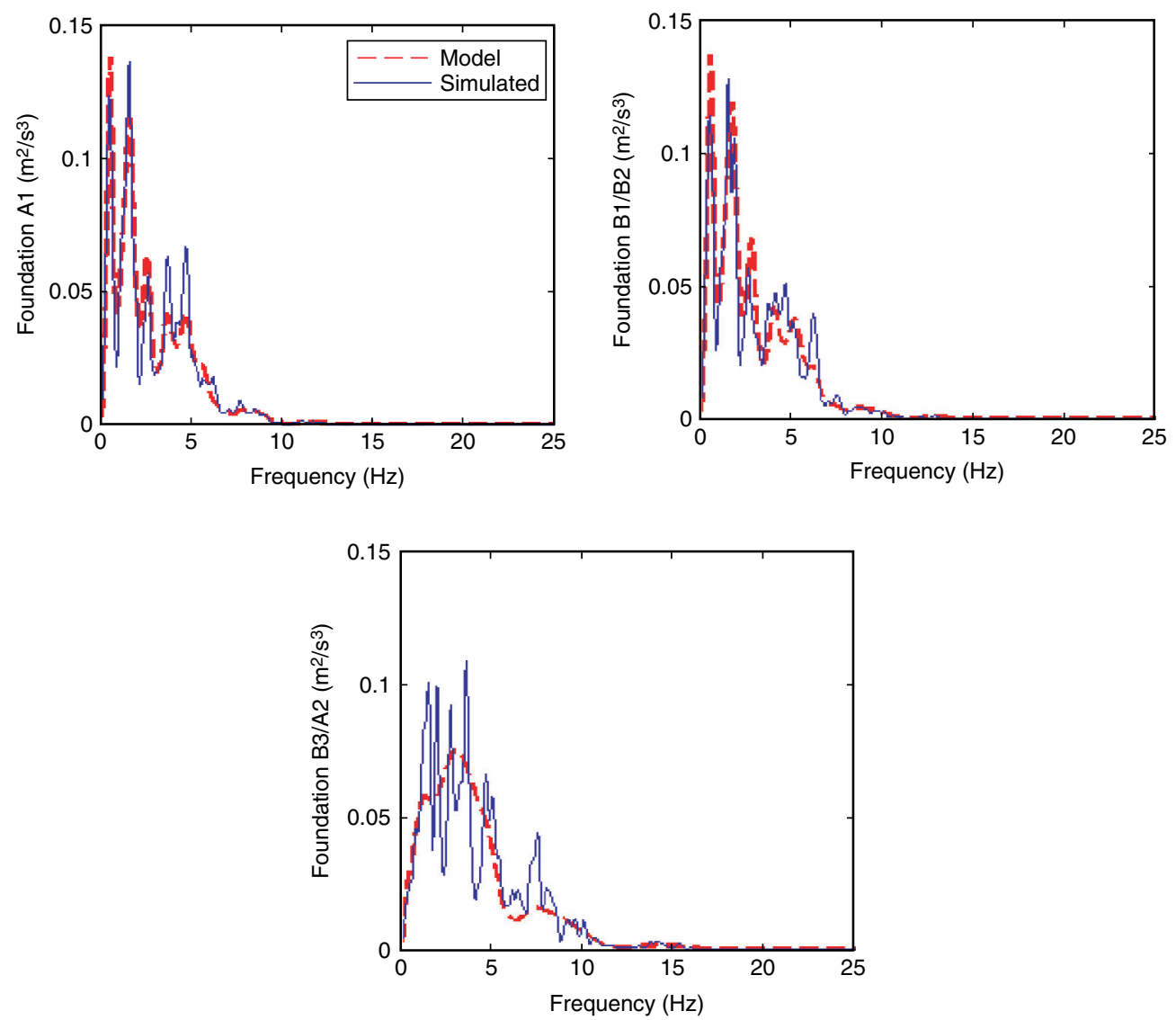

Figure 10. Comparisons of PSDs between the generated horizontal in-plane motions at different foundations with the respective theoretical values (Case 7) 

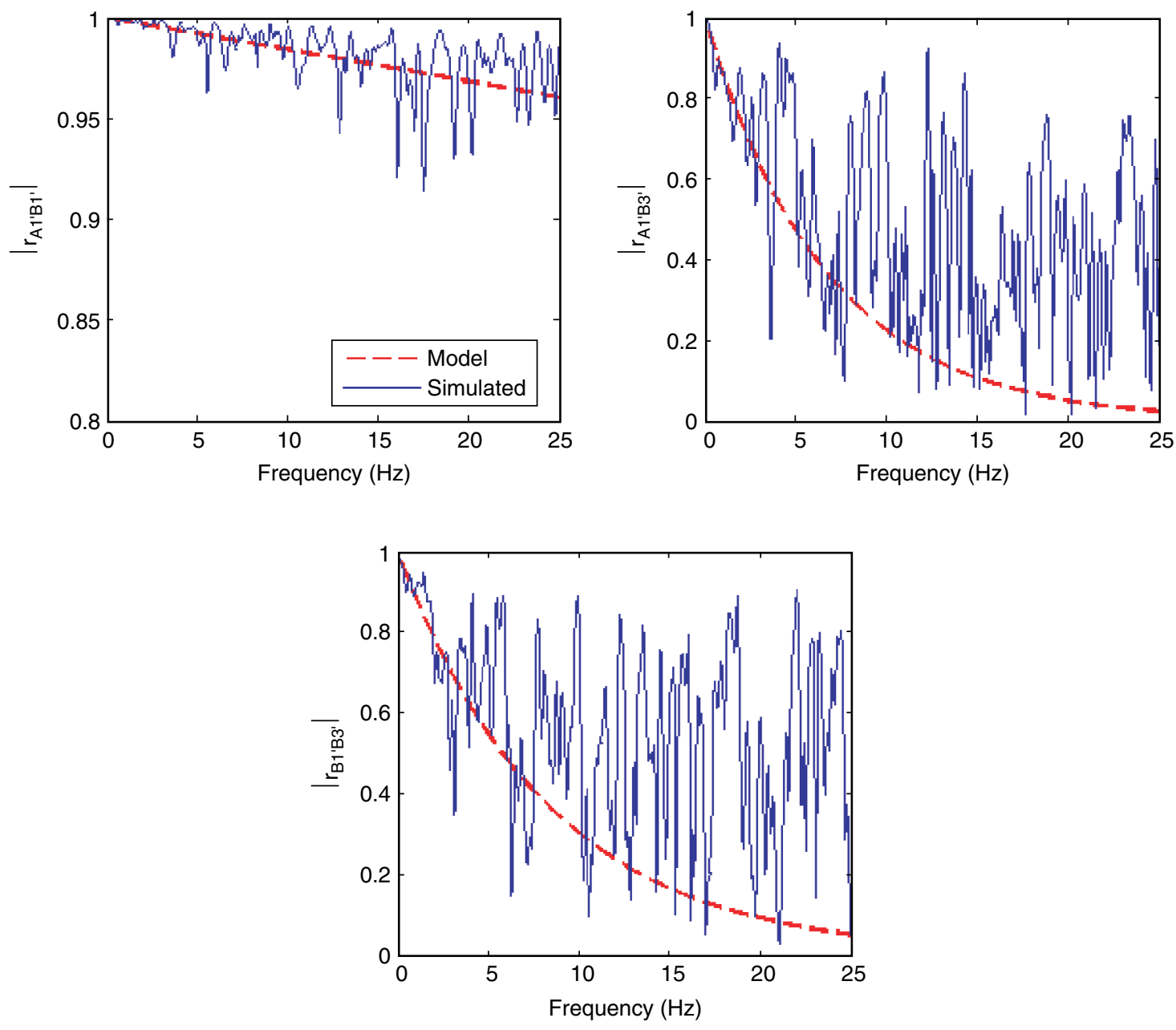

Figure 11. Comparisons of coherency loss between generated base rock accelerations with model coherency loss function

\section{EQUATIONS OF MOTION}

To analyse the seismic response of long span structures to spatially varying ground motions, two simple analytical methods are usually adopted. These are the relative motion method (RMM), which divides the structural response into a dynamic response component and a quasi-static response component, and the large mass method (LMM), which attributes fictitious large masses at each driven nodal DOFs to obtain the total response of the structure (Leger et al. 1990). RMM was well documented in many textbooks (e.g., Dynamics of Structures by Clough and Penzien 1975), interested readers can refer to these textbooks. It should be noted that for a long span structure the RMM might be very time consuming, since it requires an additional static solution at each time step used for the integration of the dynamic equilibrium equations. In addition, it requires the integration of the input ground acceleration to provide the ground displacement required for the static solution procedure. Moreover, the RMM cannot be directly extended to study the nonlinear response of multisupport structures since the superposition is used. To overcome the limitations of RMM, the LMM is usually adopted to nonlinear seismic analysis of large dimensional structures to spatially varying ground motions.

The LMM was proposed by Leger et al. (1990). In order to specify the accelerations at the support DOFs, fictitious large masses $\left(M_{l l}\right)$ are added at the driven support DOFs. To reproduce the specified acceleration, the inertia forces developed at the supports should also be considered as external driving forces. In this case, the dynamic equilibrium equation can be written as (Leger et al. 1990)

$$
\begin{aligned}
& {\left[\begin{array}{cc}
M_{s s} & M_{s b} \\
M_{b s} & M_{b b}+M_{l l}
\end{array}\right]\left\{\begin{array}{l}
\ddot{u}_{s}^{t} \\
\ddot{u}_{b}^{t}
\end{array}\right\}+\left[\begin{array}{ll}
C_{s s} & C_{s b} \\
C_{b s} & C_{b b}
\end{array}\right]\left\{\begin{array}{c}
\dot{u}_{s}^{t} \\
\dot{u}_{b}^{t}
\end{array}\right\}} \\
& +\left[\begin{array}{ll}
K_{s s} & K_{s b} \\
K_{b s} & K_{b b}
\end{array}\right]\left\{\begin{array}{c}
u_{s}^{t} \\
u_{b}^{t}
\end{array}\right\}=\left\{\begin{array}{c}
0 \\
M_{b b}+M_{u}
\end{array}\right\}\left\{\ddot{u}_{g}\right\}
\end{aligned}
$$


where $[M],[C]$ and $[K]$ are the mass, damping and stiffness matrices respectively, $\left\{\ddot{\mathrm{u}}^{t}\right\},\left\{\dot{\mathrm{u}}^{t}\right\}$ and $\left\{u^{t}\right\}$ are the absolute acceleration, velocity and displacement vectors. The subscripts, $s s, b b$ and $s b$ denote the structural DOFs, the support DOFs and coupled DOFs, in which $s$ refers to the structure and $b$ refers to the base.

The second line of Eqn 5 is

$$
\begin{aligned}
& {\left[M_{b s}\right]\left\{\ddot{u}_{s}^{t}\right\}+\left[M_{b b}+M_{l l}\right]\left\{\ddot{u}_{b}^{t}\right\}+\left[C_{b s}\right]\left\{\dot{u}_{s}^{t}\right\}+\left[C_{b b}\right]\left\{\dot{u}_{b}^{t}\right\}} \\
& +\left[K_{b s}\right]\left\{u_{s}^{t}\right\}+\left[K_{b b}\right]\left\{u_{b}^{t}\right\}=\left[M_{b b}+M_{l l}\right]\left\{\ddot{u}_{g}\right\}
\end{aligned}
$$

Since $M_{u}$ is much larger than other terms in Eqn 6, the contribution of them thus can be neglected, which results in

$$
\left\{\ddot{u}_{b}^{t}\right\} \approx\left\{\ddot{u}_{g}\right\}
$$

For the structural responses

$$
\begin{aligned}
& {\left[M_{s s}\right]\left\{u_{s}^{t}\right\}+\left[C_{s s}\right]\left\{u_{s}^{t}\right\}+\left[K_{s s}\right]\left\{u_{s}^{t}\right\}=} \\
& -\left[M_{s b}\right]\left\{u_{b}^{t}\right\}-\left[C_{s b}\right]\left\{u_{b}^{t}\right\}-\left[K_{s b}\right]\left\{u_{b}^{t}\right\} \approx \\
& -\left[M_{s b}\right]\left\{u_{g}\right\}-\left[C_{s b}\right]\left\{u_{g}\right\}-\left[K_{s b}\right]\left\{u_{g}\right\}
\end{aligned}
$$

By setting the large mass $M_{u}$ equals to about $10^{7}$ times the total mass of the bridge, it was proved that LMM is able to yield results that are almost identical to those of RMM (Leger et al. 1990).

The LMM can be conveniently implemented in ANSYS. The large masses are applied at the supporting nodes of the bridge (locations A1, A2, B1, B2 and B3 in Figure 2) by using the MASS21 element in ANSYS and the value is $10^{7}$ times the total mass of the bridge as suggested by Leger et al. (1990). The seismic excitations are applied as external forces at different driven supporting nodes, and the values equal to the large masses multiplying the corresponding accelerations at different supports.

\section{NUMERICAL RESULTS}

The nonlinear seismic response of Yeshan River Bridge is investigated in detail in this section. All the calculations are carried out by using the finite element code ANSYS. Rayleigh damping is assumed in the model to simulate energy dissipation during structural vibrations. The first two vibration modes are chosen to determine the mass and stiffness coefficients. By assuming the structural damping ratio of $5 \%$, for these two modes with the vibration frequencies of 0.6873 and $0.9778 \mathrm{~Hz}$ as shown in Figure 6, the mass matrix multiplier is obtained as 0.2537 and the stiffness matrix multiplier is 0.0096 . To investigate the influence of multi-component and spatially varying ground motions on the structural responses, seven different cases as shown in Table 2 are considered. In the last column of the table, 'FFF' and 'SSS' represent the soil conditions for the three sites are homogeneous with firm and soft soil conditions respectively, 'SSF' denotes that the soil conditions under A1 and B1/B2 are soft soil while that under B3/A2 is firm soil. To obtain relatively unbiased seismic responses of the structure, independent numerical calculations are performed by using three sets of independently simulated spatial ground motions as inputs. The mean peak responses, which are mostly concerned in engineering practice, are calculated and discussed. As pointed out by Ren and Obata (1999), seismic analysis should start from the deformed equilibrium configuration due to dead load, a static analysis is performed first and the results are applied as initial conditions in the second step dynamic seismic analysis in the present study.

For readers' easy reference, the procedure of a nonlinear seismic analysis of a CFST arch bridge are briefly summarized as follows: (1) Finite element modelling of the structure, which includes the proper modelling of geometric and material nonlinearities of the key structural components; (2) Perform modal analysis and calculate the mass and stiffness coefficients of Rayleigh damping; (3) Stochastically simulate the multi-component spatially varying ground motions at different supports of the structure; (4) Perform static analysis and obtain the initial equilibrium position of the structure; (5) Carry out nonlinear dynamic analysis. The following sections show the numerical results based on this procedure.

\subsection{Effect of Multi-Component Earthquake Excitations}

To study the influence of multi-component earthquake excitations on the seismic responses of Yeshan River Bridge, responses of the bridge subjected to longitudinal excitation only (Case 1), combined longitudinal and vertical excitations (Case 2) and simultaneous longitudinal, vertical and transverse excitations (Case 3) are calculated. To preclude the influence of ground motion spatial variations, the uniform excitation is assumed, with the inputs at locations B1/B2 and B3/A2 identical to those at location A1. Figures 12, 13 and 14 show the maximum axial forces $\mathrm{N}$, in-plane bending moments $\mathrm{Mz}$ and out-of-plane bending moments My in the upper and lower chords of the arch ribs, respectively. Since three independent calculations are performed for 


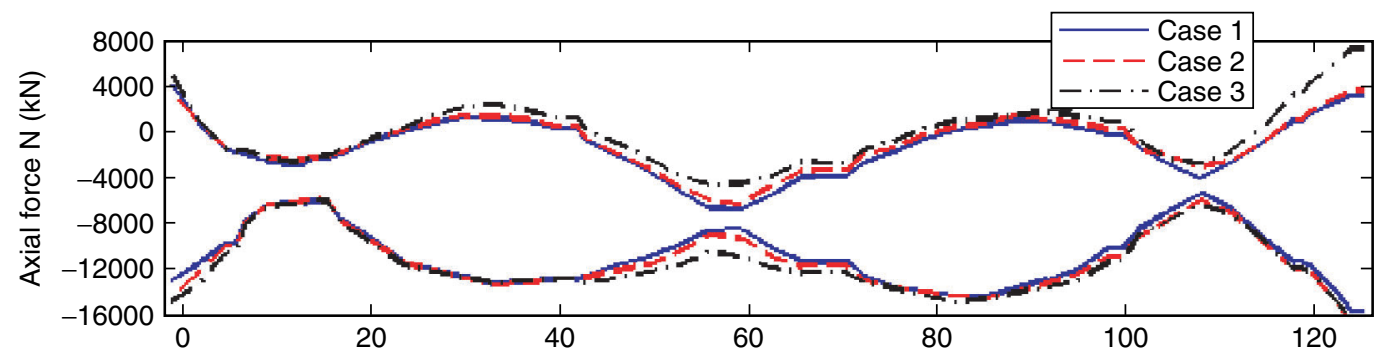

(a) Upper chord

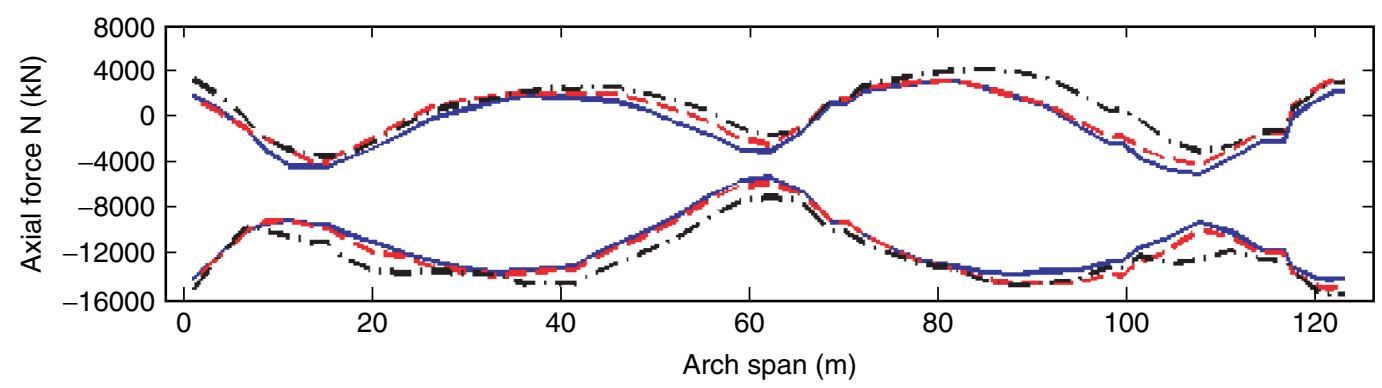

(b) Lower chord

Figure 12. Influence of multi-component earthquake excitations on the axial force $\mathrm{N}$

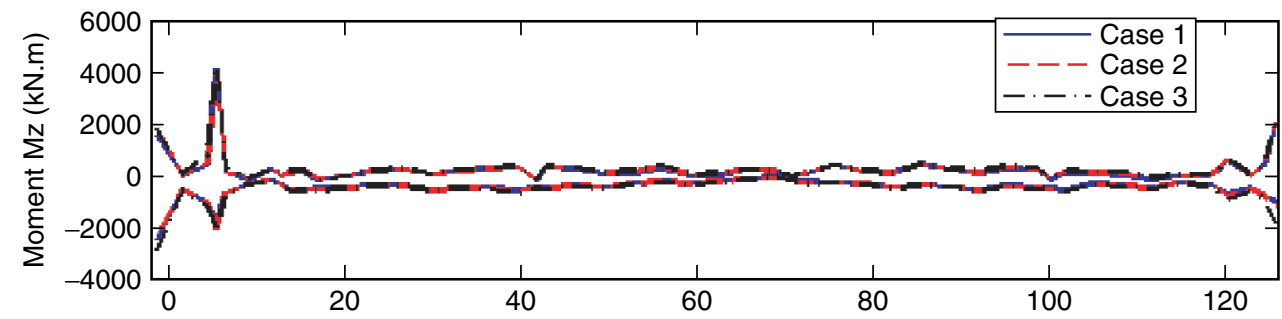

(a) Upper chord

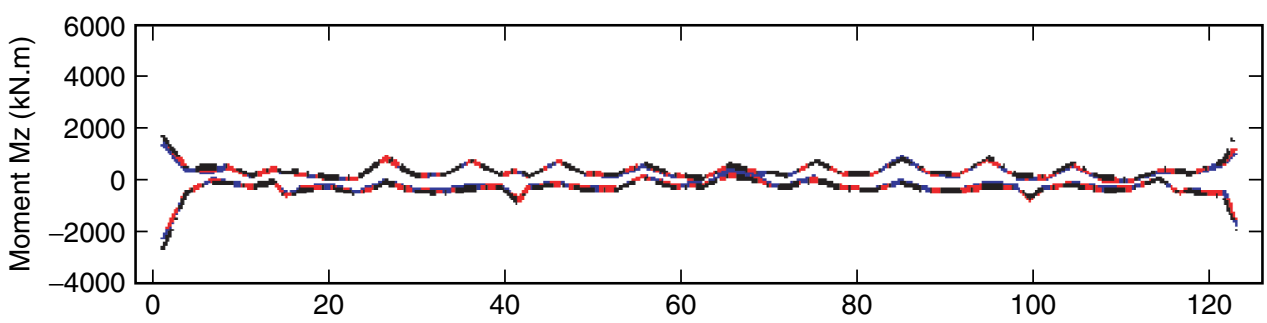

(b) Lower chord

Arch span (m)

Figure 13. Influence of multi-component earthquake excitations on the in-plane bending moment $\mathrm{Mz}$

each case, the results shown in these figures are the averaged responses.

As shown in Figure 12, when only the longitudinal excitation is considered (bold blue line), the minimum axial force appears near the middle span of the arc. This is because uniform longitudinal ground motions excite only the symmetric vibration modes of the structure (in the present study the symmetric vibration mode means the vibration mode is symmetric about the middle span since Yeshan River Bridge is asymmetric that the vault position is different from the middle span location), which results in small dynamic axial forces in the lower and upper chord members at the middle span. When the dead load of the bridge is not considered, the axial force at the middle span should be zero based on the theoretical derivations (Hao 1993). The values of axial forces at middle span in the 


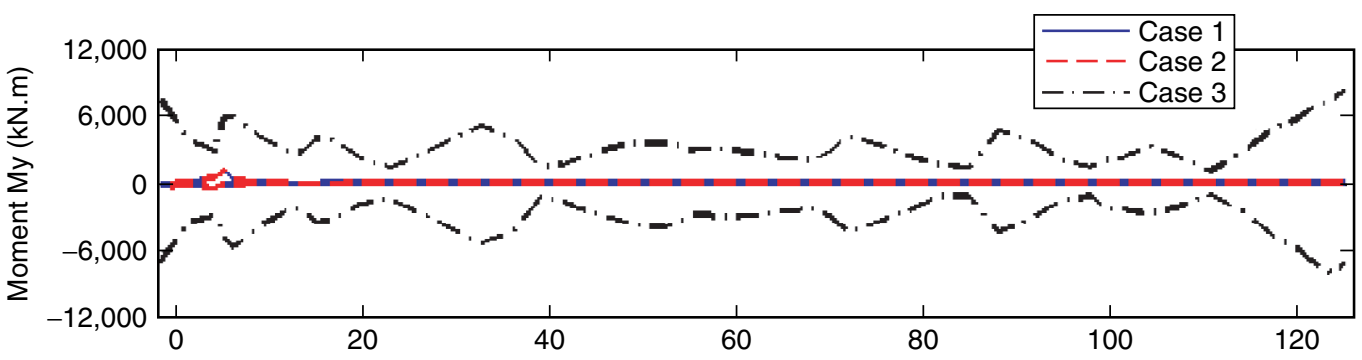

(a) Upper chord

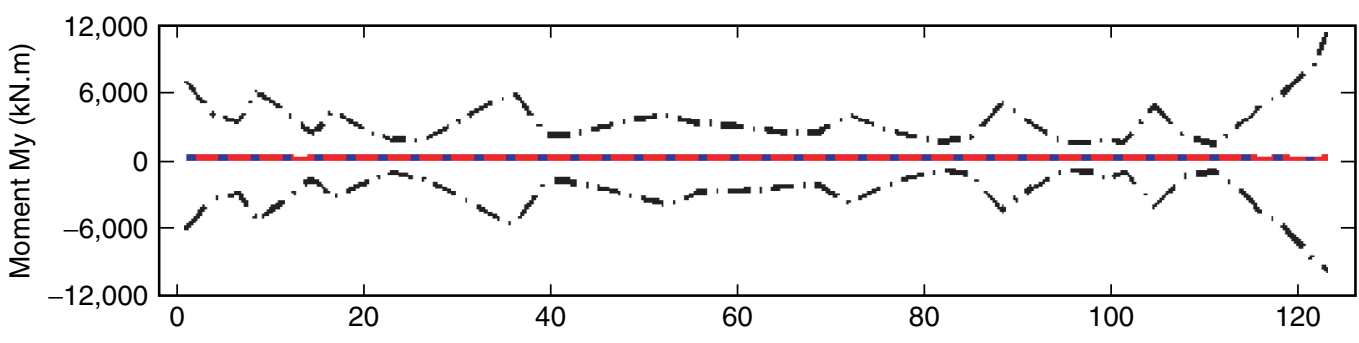

(b) Lower chord

Arch span (m)

Figure 14. Influence of multi-component earthquake excitations on the out-of-plane bending moment My

present study, however, are not zero owing to the fact that the dynamic analysis is based on the deformed configuration of the bridge as mentioned above, and the non-zero axial forces at the middle span are caused by the dead load of the bridge. It should be noted that the axial force at the vault of Yeshan River Bridge (70.375 m from the left arch springing) is not small as shown in Figure 12 due to the asymmetric geometry of the bridge. This result indicates that when uniform longitudinal excitation is considered, the minimum axial force appears at the middle span of the arc but not necessarily at the vault position. This is an obvious difference between a symmetric arch bridge, in which the vault position and the middle span coincide with each other. Special attentions should be paid when an asymmetric arch bridge is designed since the smallest thickness of the steel tube is usually selected around the vault position. This selection may lead to an unsafe design of the bridge.

As also can be seen from Figure 12, the axial forces in the arch ribs are mainly caused by the longitudinal excitation, the contribution of vertical excitation is relatively small as the axial forces result from the combined longitudinal and vertical excitations (Case 2) are almost identical to the longitudinal excitation (Case 1). This is actually as expected, since the first three vibration modes of the bridge are in the transverse direction and the first vertical mode appears as the fourth mode as shown in Figure 6, which means more energy is required to excite the vertical modes. Moreover, the amplitudes of the vertical motions are smaller than those in the horizontal directions as shown in Figures 7 and 8. It should be noted that these observations do not coincide with those obtained by Hao (1995), in which it was found that the influence of vertical ground motions cannot be neglected. This is because in the theoretical solutions (Hao 1995), only a simple circular arc was considered, and the first five vibration modes of the simple arc are in the vertical direction, the contribution of vertical motions is thus evident. This observation indicates that it is not easy to obtain a general conclusion on the influence of multi-component ground motions, the seismic responses of the structure strongly depend on the dynamic characteristics of the structure itself and the input excitation. When 3D excitations (Case 3) are considered, relatively larger axial forces are generated, especially on the right support, indicating the contribution of transverse excitations to the arch bridge responses.

Figures 13 and 14 show the influence of multicomponent ground motions on the in-plane bending moment $\mathrm{Mz}$ and out-of-plane bending moment My. As shown in Figure 13, the maximum in-plane bending moment $\mathrm{Mz}$ usually appears at the springing positions of the arch ribs. This result is consistent with those reported by $\mathrm{Wu}$ et al. (2006). As for $\mathrm{Mz}$ in the upper chord, another obvious peak can be obtained at the location of pier 2 (P2). This is because $\mathrm{P} 2$ is directly supported by the upper chord as shown in Figure 2, the weight of the deck system and the self-weight of the pier result in a large concentrated force at the P2 position, which in turn leads to a large inplane bending moment Mz. For the rest part of the ribs, relatively larger $\mathrm{Mz}$ can be obtained at the positions where 
suspenders exist owing to the concentrated forces provided by the suspenders. It also can be seen from Figure 13 that $\mathrm{Mz}$ is mainly caused by the longitudinal excitations and the influence of transverse and vertical motions can be neglected. As for the out-of-plane bending motion My as shown in Figure 14, it is obvious that My is caused by the transverse motions. Similar to the in-plane bending moment $\mathrm{Mz}$, the maximum values appear at the springing positions. Relatively larger My can also be obtained at the positions where lateral bracing systems and horizontal stiffening girder exist owing to the concentrated forces provided by them.

\subsection{Effect of Ground Motion Spatial Variations}

To study the influence of ground motion spatial variations on Yeshan River Bridge, the bridge model subjected to the simulated ground motions of Cases 3 to 5 are considered. Particularly, Case 3 corresponds to uniform ground motions, Case 4 considers spatial ground motions with wave passage effect only, and Case 5 is a general case which considers spatial ground motions with both wave passage effect and coherency loss effect. Therefore, the significance of ground motion spatial variations increases from Case 3 to Case 5. In the study, homogeneous sites with firm soil conditions are assumed and 3D excitations are considered.

Figure 15 shows the axial forces in the arch ribs when the bridge is subjected to different spatially varying ground motions. As shown, uniform ground motion will significantly underestimate the axial forces in the arch ribs, since uniform ground motion excites only the symmetric modes as mentioned above. When spatially varying ground motions are considered, the asymmetric vibration modes will be excited, and the contribution of asymmetric vibration modes are especially significant at the middle span of the bridge. Considering spatial ground motion wave passage effect (Case 4) leads to a better prediction of the axial forces in the arch ribs for Yeshan River Bridge since the results are usually slightly smaller than those obtained by the general case (Case 5) as shown in Figure 15. However, it should be noted that only intermediately correlated ground motions are considered in the present study. The coherency loss effect might be significant if the coherency loss value is relatively low.

Figures 16 and 17 show the influence of ground motion spatial variations on the in-plane bending moments $\mathrm{Mz}$ and out-of-plane bending moments $\mathrm{My}$. Different from axial forces, the influence of ground motion spatial variation is insignificant for the bending moments, and uniform excitations can give a good prediction of the bending moments.

\subsection{Effect of Local Soil Conditions}

Local soil conditions may have important influence on the seismic responses of structures because of the site filtering and amplification effect on the ground motions as mentioned above. To study the influence of local site effect, three different cases are considered. Cases 5 and 6 assume that the soil conditions under different supports are the same with Case 5 considering firm soil and Case 6 for soft soil. In Case 7, the soil conditions of the canyon are different, with supports A1 and B1/B2 located at a

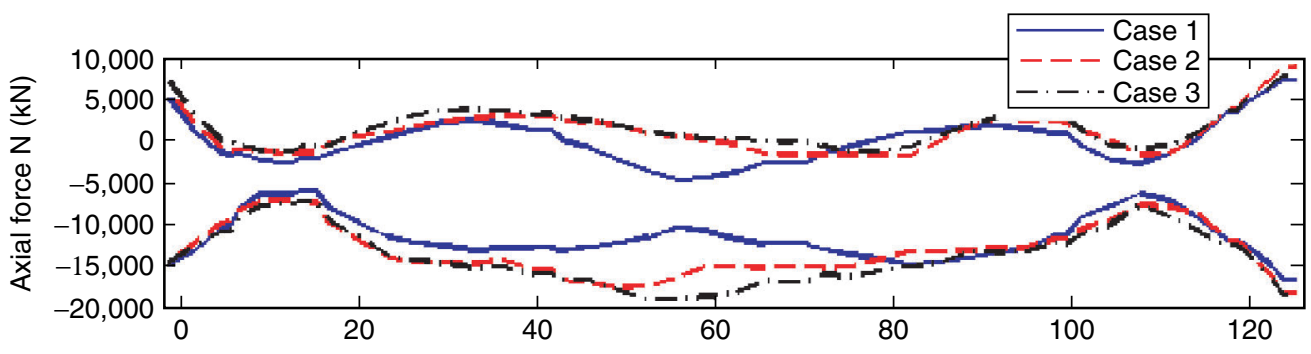

(a) Upper chord

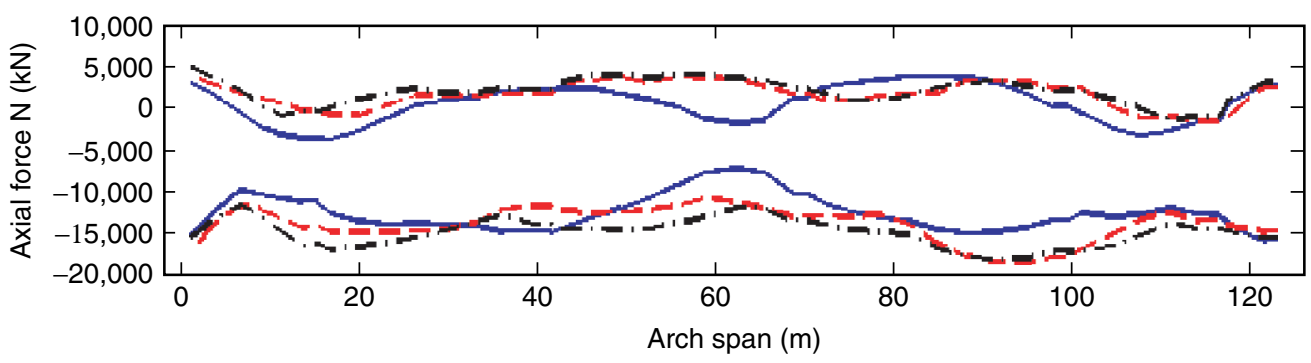

(b) Lower chord

Figure 15. Influence of ground motion spatial variations on the axial force $\mathrm{N}$ 


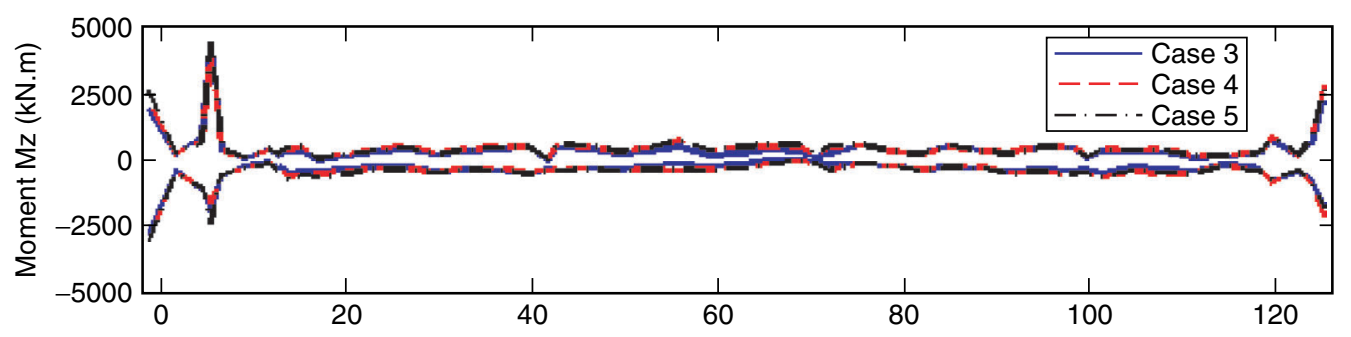

(a) Upper chord

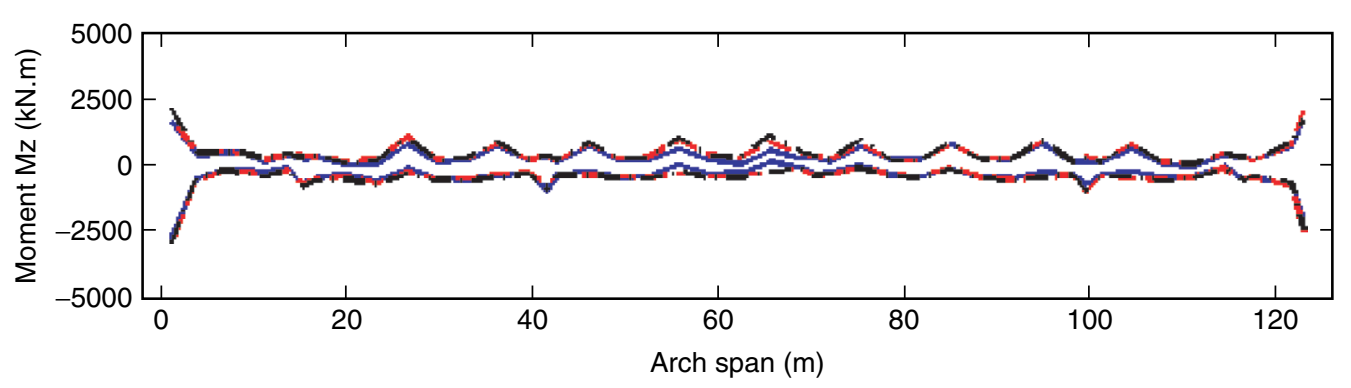

(b) Lower chord

Figure 16. Influence of ground motion spatial variations on the in-plane bending moment $\mathrm{Mz}$

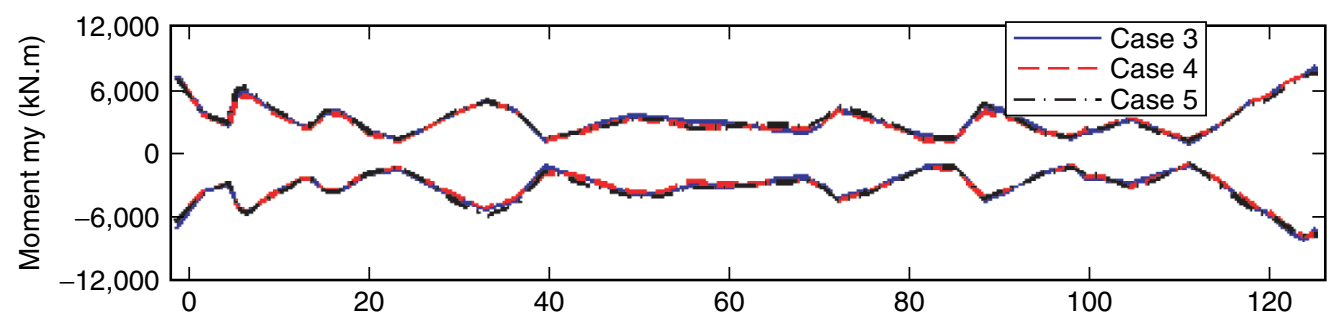

(a) Upper chord

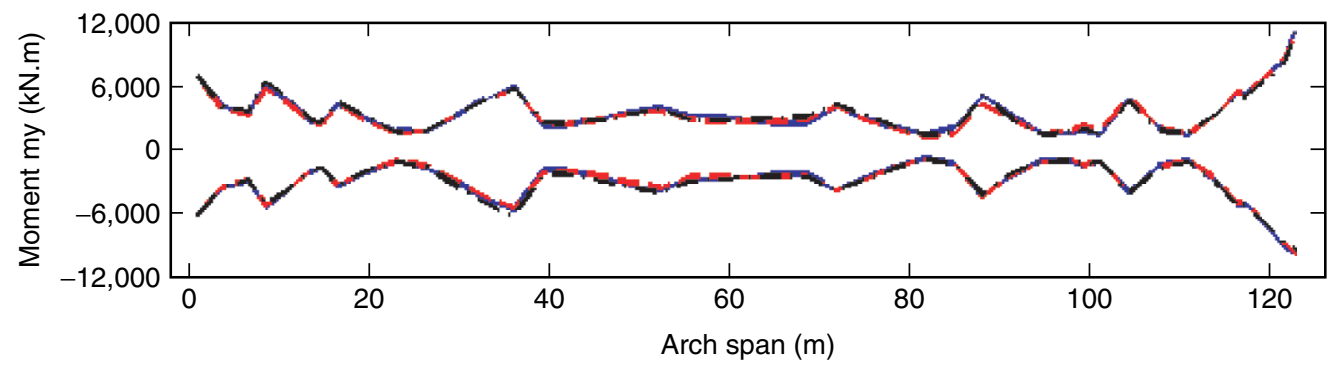

(b) Lower Chord

Figure 17. Influence of ground motion spatial variations on the out-of-plane bending moment My

soft site and B3/A2 at a firm site. For all the three cases, $3 \mathrm{D}$ spatially varying ground motions are considered and for each case the same coherency loss is assumed, the only difference between them is the site conditions.

Figure 18 shows the influence of local soil conditions on the axial forces N. As shown, site conditions substantially affect the axial forces of the arch ribs. When the bridge is located at a homogeneous site (Cases 5 and 6), softer soil conditions result in larger axial forces. This is because softer soil leads to larger ground displacement at different supports of the bridge as shown in Figure 8, which in turn gives rise to larger structural responses. It is interesting to find that when the bridge is located at a heterogeneous site (Case 7), the axial forces are the largest among the three cases. In the present study, Case 7 corresponds to a heterogeneous soil site, the ground displacements are between those of firm soil and soft soil. However, Case 7 ground motions induce the largest axial forces, indicating the significant effect of ground motion spatial variations. This might be because when heterogeneous soil conditions 


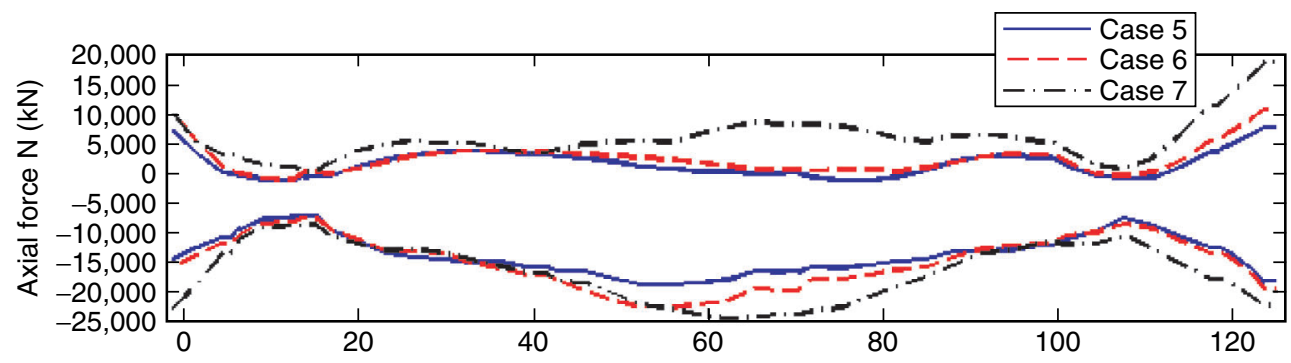

(a) Upper chord

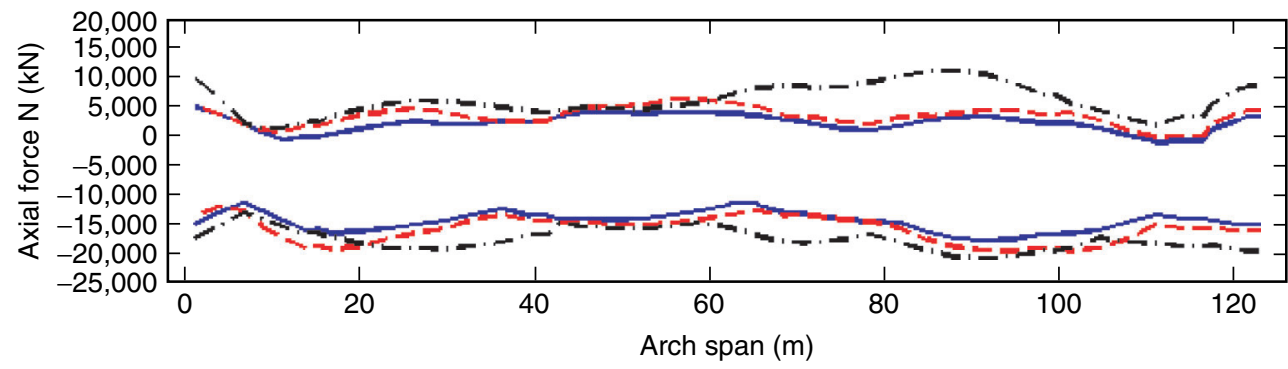

(b) Lower chord

Figure 18. Influence of local soil conditions on the axial force $\mathrm{N}$

are considered, different soil conditions will filter and amplify the base rock motions at different frequency contents and to different extent, which results in substantially different ground motions at different supports of the bridge. These different ground motions in turn lead large axial forces in the bridge. This observation is consistent with those reported by Bai et al. (2011), in which they studied the influence of heterogeneous site effect on the seismic response of a transmission tower-line system and concluded that heterogeneous site conditions result in the largest cable axial forces compared with those obtained by the homogeneous site conditions. Based on the numerical results, it is evident that neglecting the varying soil conditions on ground motion spatial variations may substantially underestimate the axial forces in the arch ribs.

Figure 19 shows the influence of local soil condition on the in-plane bending moments $\mathrm{Mz}$ in the upper and lower chords. As shown, three soil conditions result in

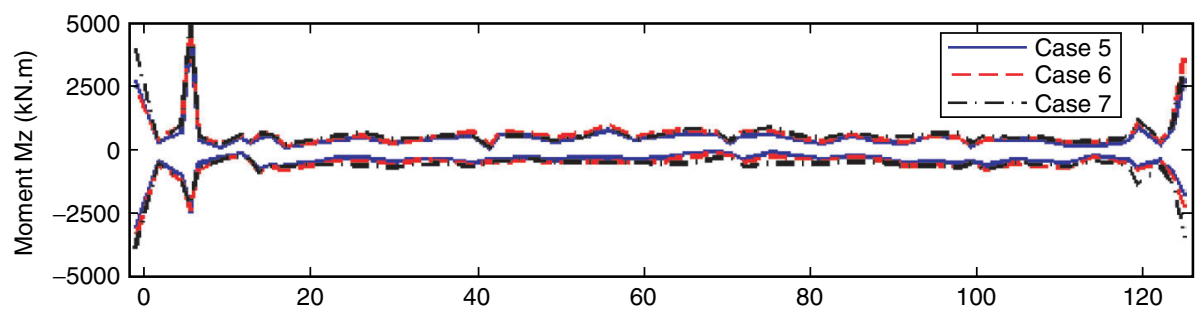

(a) Upper chord

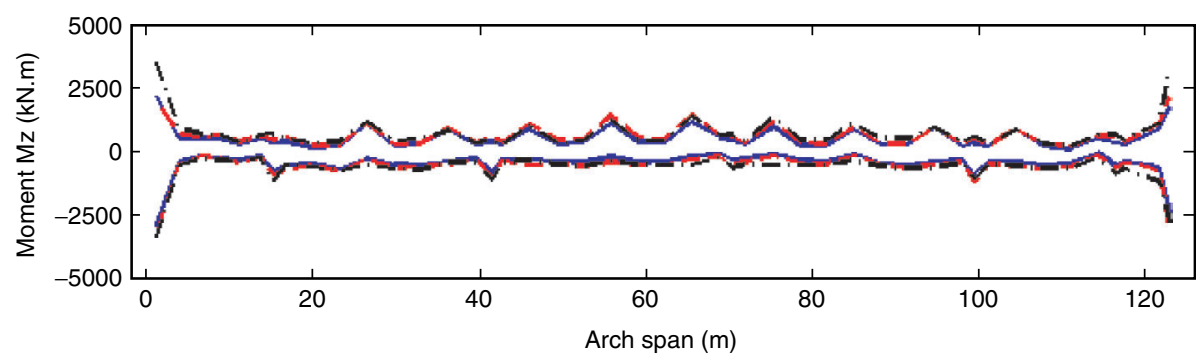

(b) Lower chord

Figure 19. Influence of local soil conditions on the in-plane bending moment $\mathrm{Mz}$ 


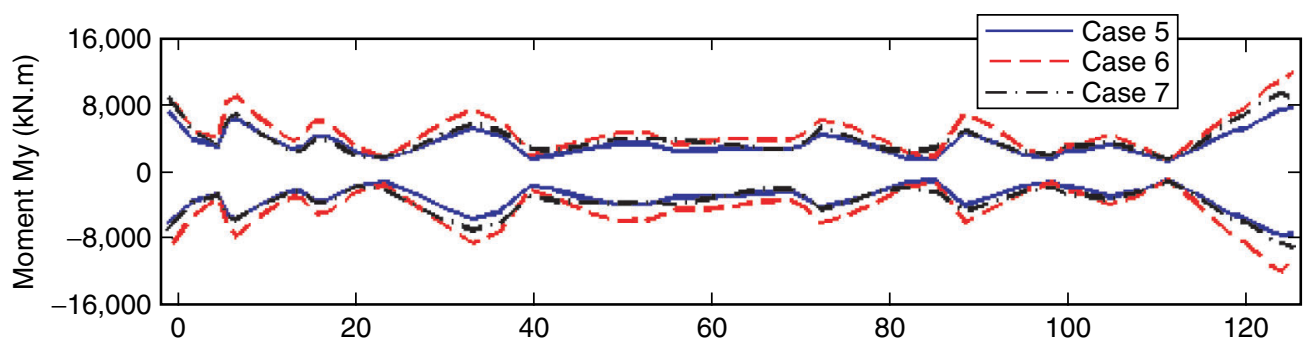

(a) Upper chord

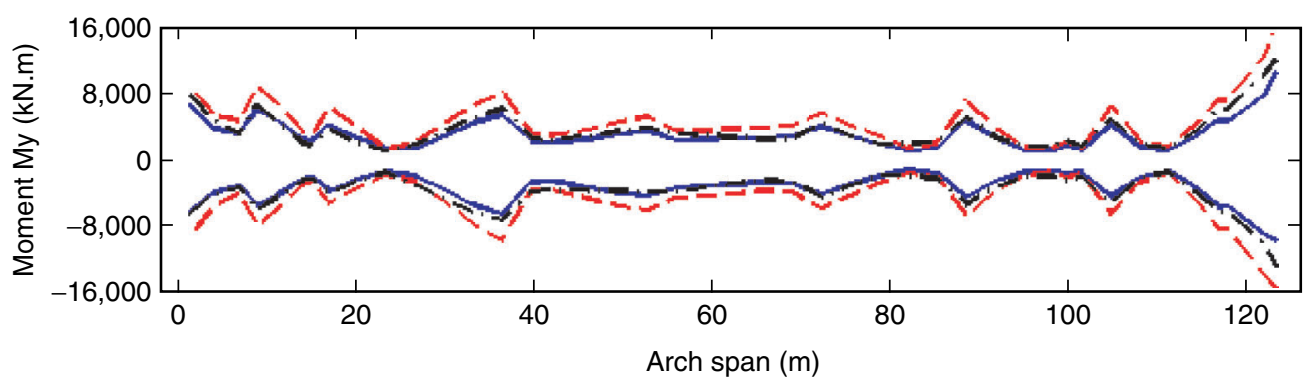

(b) Lower chord

Figure 20. Influence of local soil conditions on the out-of-plane bending moment My

almost the same in-plane bending moment $\mathrm{Mz}$ except at the springing positions, where heterogeneous soil conditions lead to a relatively larger Mz. Figure 20 shows the out-of-plane bending moments My. Different from axial forces in Figure 18, My from the Case 6 ground motions are the largest and those from Case 5 are the smallest. This is because softer soil conditions result in larger displacements at the bridge supports as shown in Figure 8. This observation indicates that out-of-plane bending moments $\mathrm{My}$ strongly depend on the ground motion displacement amplitude. On the other hand, Case 7 results in almost the same out-of-plane bending moments My as those in Case 5 though heterogeneous soil conditions are assumed in Case 7, indicating ground motion spatial variation has a relatively less effect on My.

\section{CONCLUSIONS}

This paper studies the seismic response of a CFST arch bridge located at a canyon site to multi-component spatially varying ground motions. The effects of multicomponent earthquake excitations, ground motion spatial variations and local site effect on the responses of the CFST arch bridge are investigated. Following conclusions are obtained based on the numerical results:

(1) The axial forces of the arch ribs are mainly governed by the longitudinal excitation. The transverse component of ground motion also contributes, but at a less extent to the axial force. The in-plane bending moments is generated primary by the longitudinal excitation. The contributions from the transverse and vertical ground motions to the in-plane bending moment are insignificant. Similarly, the out-of-plane bending moments are governed by the transverse excitation, and the longitudinal and vertical ground motions can be neglected.

(2) The ground motion spatial variations strongly influence the axial forces of the arch ribs. Neglecting the spatially varying ground motions may significantly underestimate the axial forces. Considering wave passage effect can give a better prediction of the axial forces in the arch ribs compared with the uniform excitation though it still underestimates the axial forces. The bending moment responses of the arch bridge considered in this study are, however, not sensitive to the ground motion spatial variations.

(3) Local site conditions significantly influence the structural responses. Heterogeneous site conditions result in the largest axial forces in the arch ribs.

It should be noted that the structural responses are determined by the structure itself and the characteristics of earthquake excitations. It is difficult to give a general conclusion from the research of a single CFST arch bridge model. However, results from this study demonstrate the importance of considering ground motion spatial variation and local site effect on the seismic responses of a CFST arch bridge. 


\section{ACKONWLEDGEMENT}

The authors acknowledge the partial financial support from ARC Linkage project LP110200906 for carrying out this research.

\section{REFERENCES}

ANSYS, Inc. (2009). ANSYS User's Manual Revision 12.1, Canonsburg, Pennsylvania, USA.

Bai, F., Hao, H. and Li, H. (2010). "Seismic response of a steel trussed arch structure to spatially varying earthquake ground motions including site effect", Advances in Structural Engineering, Vol. 13, No. 6, pp. 1089-1103.

Bai, F., Hao, H., Bi, K. and Li, H. (2011). "Seismic response analysis of transmission tower-line system on a heterogeneous site to multi-component spatial ground motions", Advances in Structural Engineering, Vol. 14, No. 3, pp. 457-474.

Bai, L. (2008). "Seismic response analysis of long-span CFST arch bridge”, China Railway Science, Vol. 29, No. 6, pp. 41-45. (in Chinese)

Bi, K. and Hao, H. (2011). "Influence of irregular topography and random soil properties on coherency loss of spatial seismic ground motions", Earthquake Engineering and Structural Dynamics, Vol. 40, No. 9, pp. 1045-1061.

Bi, K. and Hao, H. (2012). "Modelling and simulation of spatially varying earthquake ground motions at sites with varying conditions", Probabilistic Engineering Mechanics, Vol. 29, pp. $92-104$.

Bi, K., Hao, H. and Chouw, N. (2010). "Required separation distance between decks and at abutments of a bridge crossing a canyon site to avoid seismic pounding", Earthquake Engineering and Structural Dynamics, Vol. 39, No. 3, pp. 303-323.

Bi, K., Hao, H. and Chouw, N. (2011). "Influence of ground motion spatial variation, site condition and SSI on the required separation distances of bridge structures to avoid seismic pounding", Earthquake Engineering and Structural Dynamics, Vol. 40, No. 9, pp. 1027-1043.

Clough, R. and Penzien, J. (1975). Dynamics of Structures, McGraw-Hill, New York, USA.

Der Kiureghian, A. (1980). "Structural response to stationary excitation", Journal of Engineering Mechanics Division, ASCE, Vol. 106, No. 6, pp. 1195-1213.

Der Kiureghian, A. (1996). "A coherency model for spatially varying ground motions", Earthquake Engineering and Structural Dynamics, Vol. 25, No. 1, pp. 99-111.

Hao, H. (1993). "Arch response to correlated multiple excitations", Earthquake Engineering and Structural Dynamics, Vol. 22, No. 5, pp. 389-404.

Hao, H. (1995). "Ground motion spatial variation effects on circular arch responses", Journal of Engineering Mechanics, ASCE, Vol. 120, No. 11, pp. 2326-2341.

Hao, H., Oliveira, C.S. and Penzien, J. (1989). "Multiple-station ground motion processing and simulation based on SMART-1 array data", Journal of Nuclear Engineering and Design, Vol. 111, No. 3, pp. 293-310.
Harichandran, R.S., Hawwari, A. and Sweiden, B.N. (1996). "Response of long-span bridges to spatially varying ground motion", Journal of Structural Engineering, ASCE, Vol. 112, No. 5, pp. 476-484.

Japan Road Association (2002). Design Specifications for Highway Bridges, Part V: Seismic Design, Tokyo, Japan.

Leger, P., Ide, I.M. and Paultre, P. (1990). "Multiple-support seismic analysis of large structures", Computers and Structures, Vol. 36, No. 6, pp. 1153-1158.

Nakamura, S., Tanaka, H. and Kato, K. (2009). "Static analysis of cable-stayed bridge with CFT arch ribs", Journal of Constructional Steel Research, Vol. 65, No. 4, pp. 776-783.

Ren, W.X. and Obata, M. (1999). "Elastic-plastic seismic behaviour of long span cable-stayed bridges", Journal of Bridge Engineering, ASCE, Vol. 4, No. 3, pp. 194-203.

Sobczky, K. (1991). Stochastic Wave Propagation, Kluwer Academic Publishers, Netherlands.

Su, L., Dong, S.L. and Kato, S. (2007). "Seismic design for steel trussed arch to multi-support excitations", Journal of Constructional Steel Research, Vol. 63, No. 6, pp. 725-734.

Tajimi, H. (1960). "A statistical method of determining the maximum response of a building structure during an earthquake", Proceedings of $2^{\text {nd }}$ World Conference on Earthquake Engineering, Tokyo, Japan, pp. 781-796.

Uniform Building Code (1997). Structural Design Requirements, International Conference of Building Officials, Whittier, California, USA.

Wolf, J.P. (1985). Dynamic Soil-Structure Interaction, Prentice Hall, Englewood Cliffs, New Jersey, USA.

Wu, Q., Yoshimura, M., Takahashi, K., Nakamura, S. and Nakamura, T. (2006). "Nonlinear seismic properties of the Second Saikai Bridge: A concrete filled tubular (CFT) arch bridge", Engineering Structures, Vol. 28, No. 2, pp. 163-182.

Yoshimura, M., Wu, Q., Takahashi, K., Nakamura, S. and Furukawa, K. (2006). "Vibration analysis of the Second Saikai Bridge-a concrete filled tubular (CFT) arch bridge", Journal of Sound and Vibration, Vol. 290, No. 1-2, pp. 388-409.

Zanardo, G., Pellegrino, C., Bobisut, C. and Modena, C. (2004). "Performance evaluation of short span reinforced concrete arch bridges", Journal of Bridge Engineering, ASCE, Vol. 9, No. 5, pp. 424-434.

Zhao, C. and Zhou, Z. (2007). "Stationary stochastic response of long-span CFST arch bridge under the multi-component and multi-support seismic excitation", World Earthquake Engineering, Vol. 23, No. 4, pp. 66-71. (in Chinese)

Zong, Z., Jaishi, B., Ge, J. and Ren, W.X. (2005). "Dynamic analysis of a half-through concrete-filled steel tubular arch bridge", Engineering Structures, Vol. 27, No. 1, pp. 3-15.

\section{NOTATION}

$\sigma_{c B}$ : yield stress of confined concrete

$\varepsilon_{c B}$ : yield strain of confined concrete

$\sigma_{c k}: \quad$ concrete strength

$D \quad$ outer diameter of steel tube

$S_{g} \quad$ power spectral density function on the base rock 
$\omega_{f} \quad$ central frequency of high pass filter

$\xi_{f} \quad$ damping ratio of high pass filter

$\omega_{g} \quad$ central frequency of Tajimi-Kanai power spectral density function

$\xi_{g} \quad$ damping ratio of Tajimi-Kanai power spectral density function

$\Gamma \quad$ scale factor depending on the ground motion intensity

$\gamma_{j^{\prime} k^{\prime}}(i \omega)$ coherency loss function between the ground motions at points $j$ ' and $k^{\prime}$

$d_{j^{\prime} k^{\prime}} \quad$ projected distance between points $j^{\prime}$ and $k^{\prime}$ in the wave propagation direction

$\alpha \quad$ incident angle of incoming wave to the soil site

$\beta$ : $\quad$ coefficient depending on the level of coherency loss $v_{a p p} \quad$ apparent wave velocity on the base rock

$T$ duration of simulated time history

$M \quad$ mass matrix

$C \quad$ viscous damping matrix

$K \quad$ stiffness matrix

ss $\quad$ structural degrees of freedom

$b b \quad$ support degrees of freedom

$s b \quad$ coupled degrees of freedom

$M_{l l} \quad$ large mass matrix

$\left\{\ddot{u}^{t}\right\}$ : absolute acceleration vector of structural response

$\left\{\dot{u}^{t}\right\}$ : absolute velocity vector of structural response

$\left\{u^{t}\right\}$ : absolute displacement vector of structural response

$\left\{\ddot{u}_{g}\right\}:$ input acceleration vector 
